\title{
The efficacy of immune checkpoint inhibitors in thoracic malignancies
}

\author{
Jordi Remon $\mathbb{1}^{1}$, Francesco Facchinetti ${ }^{2}$ and Benjamin Besse ${ }^{3,4}$ \\ Number 9 in the Series "Thoracic oncology" \\ Edited by Rudolf Huber and Peter Dorfmüller
}

${ }^{1}$ Dept of Medical Oncology, Centro Integral Oncológico Clara Campal (HM-ClOCC), Hospital HM Delfos, HM Hospitales, Barcelona, Spain. ${ }^{2}$ Université Paris-Saclay, Institut Gustave Roussy, Inserm, Biomarqueurs Prédictifs et Nouvelles Stratégies Thérapeutiques en Oncologie, Villejuif, France. ${ }^{3}$ Dept of Cancer Medicine, Gustave Roussy Cancer Campus, Villejuif, France. ${ }^{4}$ Université Paris-Saclay, Paris, France.

Corresponding author: Benjamin Besse (Benjamin.Besse@gustaveroussy.fr)

Shareable abstract (@ERSpublications)

Immunotherapy has shifted the treatment paradigm and improved overall survival in non-small cell lung cancer, small-cell lung cancer and malignant pleural mesothelioma https://bit.ly/3dPg31d

Cite this article as: Remon J, Facchinetti F, Besse B. The efficacy of immune checkpoint inhibitors in thoracic malignancies. Eur Respir Rev 2021; 30: 200387 [DOI: 10.1183/16000617.0387-2020].

Copyright @The authors 2021

This version is distributed under the terms of the Creative Commons Attribution Non-Commercial Licence 4.0. For commercial reproduction rights and permissions contact permissions@ersnet.org

Received: 8 Dec 2020 Accepted: 18 Feb 2021

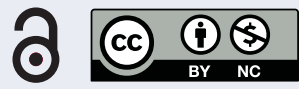

\section{Abstract}

The advent of immune checkpoint inhibitors (ICIs) has rapidly transformed the treatment paradigm for multiple cancer types, including thoracic malignancies. In advanced non-small cell lung cancer (NSCLC), ICIs have shifted treatment paradigm and improved overall survival reaching almost one-third of patients alive at 5 years. ICIs therapies have also modified the therapeutic strategy in first-line setting in metastatic small-cell lung cancer (SCLC) patients as well as in malignant pleural mesothelioma (MPM) improving the overall survival compared with standard treatment. This phenomenon is of huge relevance as both SCLC and MPM were considered orphan diseases without any significant improvement in the therapeutic strategy in the first-line setting during the last 15 years. In this review, we aim to review the efficacy of ICI in thoracic malignancies either in monotherapy or in combination, according to predictive biomarkers, and to the US Food and Drug Administration and the European Medicines Agency approvals of treatment strategies. We address the efficacy of these agents, especially in NSCLC according to PD-L1 expression and histologic subtype.

\section{Introduction}

The advent of immune checkpoint inhibitors (ICIs) has rapidly transformed the treatment paradigm for multiple cancer types, including thoracic malignancies. Over the last decade, starting from the initial approval of cytotoxic T-lymphocyte antigen 4 (CTLA-4) inhibitors in metastatic melanoma in 2011, programmed death (ligand) 1 (PD-(L)1) inhibitors are now a routine part of treatment for more than 20 different indications. In advanced non-small cell lung cancer (NSCLC) patients this shift in the treatment paradigm has mainly been driven in part by long term overall survival benefit and durable responses with these drugs, which occurred regardless of the treatment line status and also in PD-L1 unselected NSCLC patients [1-3]. ICI strategy have also modified the therapeutic strategy in first-line setting in metastatic small-cell lung cancer (SCLC) patients [4-6], being the new standard of care worldwide, although the magnitude of benefit does not mirror the one reported in NSCLC. Likewise, ICIs have also being tested in malignant pleural mesothelioma (MPM) [7] and thymic epithelial tumours (TET) with promising activity [8]. Here we aim to review the efficacy of ICI in thoracic malignancies either in monotherapy or in combination, according to predictive biomarkers, and to the US Food and Drug Administration (FDA) and the European Medicines Agency (EMA) approvals of treatment strategies. A special focus on the immune context of "rare" thoracic tumours (SCLC, MPM and TET) will be also provided, in order to discuss the space for immunotherapy in these diseases. 
Non-small cell lung cancer

Dealing with biomarkers in advanced NSCLC: PD-L1

Better predictors for response to immunotherapy are critical for its optimal use, and different predictive biomarkers have been tested. The two most explored predictive biomarkers are PD-L1 expression and tumour mutational burden (TMB). In NSCLC, PD-L1 expression has been associated with greatly improved overall survival under ICI [2, 9, 10]. Indeed, the survival benefit with ICI seems higher as higher is the PD-L1 expression [11]. However, as different immunohistochemistry (IHC) assays exist for assessing PD-L1 expression, reporting discordant results in some clinical situations, the Blueprint phase 2 PD-L1 IHC Assay Comparison Project was launched to provide information on the analytical and clinical comparability of four PD-L1 IHC assays used in clinical trials. The study revealed that three out of the five IHC assays for assessing PD-L1 expression were closely aligned on tumour cell staining (22C3, 28-8, and SP263 assays), whereas the SP142 assay exhibited fewer stained tumour cells overall, and higher sensitivity with the 73-10 assay to detect PD-L1 expression on thymic carcinomas [12]. Of note PD-L1 expression in immune cells has also been correlated with ICI efficacy [13]. However, PD-L1 is not the optimal or perfect predictive biomarker as unfortunately there is still a subset of patients who do not benefit of ICI despite having tumours with high PD-L1 expression. Furthermore, it has been observed that patients with PD-L1 negative tumours can also get benefit of ICI strategy. Finally, PD-L1 varies substantially across different anatomical sites and changes during the clinical course [14]. Despite these limitations, PD-L1 remains the only predictive biomarker available in clinical practice thus far, and PD-L1 testing is required for immunotherapy selection.

\section{$P D-L 1$ and first-line treatment with $I C I$ in NSCLC}

Currently, according to several phase III clinical trials, in advanced NSCLC patients without druggable genomic alterations (namely epidermal growth factor receptor (EGFR) mutations and anaplastic lymphoma kinase $(A L K)$ rearrangements), upfront treatment with ICI is the new standard of care. All these trials have reported overall survival benefit with ICIs compared with platinum-based chemotherapy (table 1). This survival benefit occurred:

1) in trials testing ICIs as monotherapy in selected patients whose tumours expressed PD-L1 (KEYNOTE-024 [15], KEYNOTE-042 [16]); IMPOWER 110 [17] and EMPOWER-Lung 1 [18]);

2) in trials enrolling unselected patients and testing ICIs in combination with

- other ICIs, such as anti-CTLA4 agents (CheckMate 227 [19, 20], testing nivolumab plus ipilimumab)

- chemotherapy, in non-squamous (KEYNOTE-189 [21], IMpower130 [22], IMpower150 [23, 24], ORIENT-11 [25]) and in squamous histologies (KEYNOTE-407 [26], ORIENT-12 [27])

- other ICIs and chemotherapy (CheckMate 9LA [28], testing nivolumab and ipilimumab plus 2 cycles of platinum-based chemotherapy according histologic subtype).

Some of these strategies have already been approved by either European or US health authorities, the EMA and the FDA respectively (table 1). However, there are negative trials with ICI in first-line setting, even in selected patients, such as the phase III CheckMate 026 trial [29], IMpower132 [30], IMpower131 [31], and the MYSTIC trial [32]. In the CheckMate 026 trial, nivolumab improved neither progression free survival (PFS) nor overall survival, compared with chemotherapy in advanced NSCLC with PD-L1 $15 \%$ [29]. The IMpower132 [30] only improved the PFS but not the co-primary overall survival endpoint. Similarly, the MYSTIC trial did not meet its primary end points of improved overall survival with durvalumab versus chemotherapy or improved overall survival or PFS with durvalumab plus tremelimumab versus chemotherapy in patients with $\geqslant 25 \%$ of tumour cells expressing PD-L1 [32].

PD-L1 and clinical trials with chemotherapy-sparing strategies in NSCLC

Four clinical trials support PD-L1 testing as an optimal biomarker for selecting patients that may benefit of ICI as monotherapy in first-line setting. In the KEYNOTE-024 trial, a substantial survival benefit with first-line pembrolizumab compared with chemotherapy was shown in tumours with a PD-L1 threshold $\geqslant 50 \%$, with a 5-year overall survival of $32 \%$ with pembrolizumab versus $16 \%$ with chemotherapy, leading approval by both the EMA and the FDA [15, 33]. Likewise, the KEYNOTE-042 [16] trial reported survival benefit with pembrolizumab compared with chemotherapy in PD-L1 $\geqslant 1 \%$ tumours. However, an exploratory analysis reported that the survival benefit was mostly generated by the subgroup of patients with high PD-L1 expression ( $\geqslant 50 \%$ ), with no survival benefit with pembrolizumab monotherapy compared with chemotherapy in tumours with PD-L1 expression 1-49\% (13.4 months versus. 12.1 months; HR 0.91, 95\% CI: 0.77-1.09). The IMpower110 trial [34] did not report survival benefit with atezolizumab compared with chemotherapy in the whole population (tumours with PD-L1 $1 \%$ ); however, in the subgroup analysis reported a significant survival improvement with atezolizumab only limited to the subgroup of tumours with high PD-L1-expression. Finally, the EMPOWER-lung 1 trial reported a survival benefit with cemiplimab (anti-PD1) compared with 


\begin{tabular}{|c|c|c|c|c|c|c|c|c|}
\hline Trial & Schedule & $\mathrm{n}$ & $\begin{array}{l}\text { OS months } \\
\text { HR }(95 \% \mathrm{Cl})\end{array}$ & $\begin{array}{l}\text { PD-L1 <1\% } \\
\text { HR }(95 \% \mathrm{Cl})\end{array}$ & $\begin{array}{l}\text { PD-L1 1-49\% } \\
\text { HR (95\% CI) }\end{array}$ & $\begin{array}{l}\text { PD-L1 } \geqslant 50 \% \\
\text { HR }(95 \% \mathrm{Cl})\end{array}$ & $\begin{array}{c}\text { Grade } \geqslant 3 \\
\text { AE }(\%)\end{array}$ & $\begin{array}{c}\text { Discontinuations } \\
(\%)\end{array}$ \\
\hline CheckMate 026 [29] & $\mathrm{N}$ versus $\mathrm{CT}(\mathrm{PD}-\mathrm{L} 1 \geqslant 5 \%)$ & 423 & $\begin{array}{l}14.4 \text { versus } 13.2 \\
1.02(0.80-1.30)\end{array}$ & Not tested & & $\begin{array}{c}1.07 \\
(0.77-1.49)\end{array}$ & $\begin{array}{c}18 \% \text { versus } \\
51 \%\end{array}$ & \\
\hline $\begin{array}{l}\text { CheckMate } 227[19, \\
20]^{\#, 4}\end{array}$ & $\begin{array}{l}\mathrm{N}+\text { I versus } \mathrm{CT} \text {, Part } 1 \text { (All } \\
\text { comers) }\end{array}$ & 1166 & $\begin{array}{l}17.1 \text { versus } 14.9^{\S} \\
0.76(0.67-0.93)\end{array}$ & $\begin{array}{c}0.64 \\
(0.51-0.81)^{f}\end{array}$ & $\begin{array}{c}0.94 \\
(0.73-1.12)^{f}\end{array}$ & $\begin{array}{c}0.70 \\
(0.55-0.90)^{f}\end{array}$ & $\begin{array}{c}33 \% \text { versus } \\
36 \%\end{array}$ & $12 \%$ versus $5 \%$ \\
\hline $\begin{array}{l}\text { KEYNOTE } 024 \\
{[35]^{\#, 4}}\end{array}$ & $\begin{array}{c}\mathrm{P} \text { versus } \mathrm{CT} \\
(\mathrm{PD}-\mathrm{L} 1 \geqslant 50 \%)\end{array}$ & 305 & $\begin{array}{l}26.3 \text { versus } 14.2 \\
0.65(0.50-0.86)\end{array}$ & Not tested & Not tested & $\begin{array}{c}0.65 \\
(0.50-0.86)\end{array}$ & $\begin{array}{c}31 \% \text { versus } \\
53 \%\end{array}$ & $14 \%$ versus $11 \%$ \\
\hline $\begin{array}{l}\text { KEYNOTE } 042 \\
{[16]^{\#, 9]}}\end{array}$ & $\mathrm{P}$ versus $\mathrm{CT}(\mathrm{PD}-\mathrm{L} 1 \geqslant 1 \%)$ & 1274 & $\begin{array}{l}16.4 \text { versus } 12.1^{\S} \\
0.82(0.71-0.93)\end{array}$ & Not tested & $\begin{array}{c}0.91 \\
(0.77-1.09)^{f}\end{array}$ & $\begin{array}{c}0.70 \\
(0.58-0.86)\end{array}$ & $\begin{array}{c}18 \% \text { versus } \\
41 \%\end{array}$ & $10 \%$ versus $10 \%$ \\
\hline IMpower $110[17]^{\#}$ & $\mathrm{~A}$ versus $\mathrm{CT}(\mathrm{PD}-\mathrm{L} 1 \geqslant 1 \%)$ & 572 & $\begin{array}{l}17.5 \text { versus } 14.1 \\
0.83(0.65-1.07)\end{array}$ & Not tested & $\begin{array}{c}0.83 \\
(0.65-1.07)\end{array}$ & $\begin{array}{c}0.59 \\
(0.40-0.89)\end{array}$ & $\begin{array}{c}17 \% \text { versus } \\
48 \%\end{array}$ & $6 \%$ versus $16 \%$ \\
\hline $\begin{array}{l}\text { EMPOWER-lung } 1 \\
\text { [18] }\end{array}$ & $\begin{array}{l}\text { C versus CT } \\
(\mathrm{PD}-\mathrm{L} 1 \geqslant 50 \%)\end{array}$ & 563 & $\begin{array}{l}\text { NR versus } 14.2 \\
0.57(0.42-0.77)\end{array}$ & Not tested & Not tested & $\begin{array}{c}0.57 \\
(0.42-0.77)\end{array}$ & $\begin{array}{c}37 \% \text { versus } \\
49 \%\end{array}$ & $4.2 \%$ versus $2.3 \%$ \\
\hline $\begin{array}{l}\text { CheckMate-9LA } \\
{[28]^{\#, \text { I }}}\end{array}$ & $\begin{array}{c}\mathrm{N}+\mathrm{I}+\mathrm{CT} \text { versus } \mathrm{CT} \text { (All } \\
\text { comers) }\end{array}$ & 719 & $\begin{array}{l}15.6 \text { versus } 10.9 \\
0.66(0.55-0.80)\end{array}$ & $\begin{array}{c}0.62 \\
(0.45-0.85)\end{array}$ & $\begin{array}{c}0.61 \\
(0.44-0.84)\end{array}$ & $\begin{array}{c}0.66 \\
(0.44-0.99)\end{array}$ & $\begin{array}{c}47 \% \text { versus } \\
38 \%\end{array}$ & $19 \%$ versus $7 \%$ \\
\hline $\begin{array}{l}\text { CCTG BR.34 } \\
{[40]}\end{array}$ & $\begin{array}{c}\mathrm{D}+\mathrm{T}+\mathrm{CT} \text { versus } \mathrm{D}+\mathrm{T} \text { (All } \\
\text { comers) }\end{array}$ & 301 & $\begin{array}{l}16.6 \text { versus } 14.4 \\
0.88(0.67-1.16)\end{array}$ & $\begin{array}{c}0.61 \\
(0.40-0.92)\end{array}$ & Not reported & $\begin{array}{c}0.61 \\
(0.32-1.19)\end{array}$ & $\begin{array}{c}82 \% \text { versus } \\
14 \%\end{array}$ & $23 \%$ versus $14 \%$ \\
\hline $\begin{array}{l}\text { KEYNOTE } 189 \\
{[21]^{\#, 9}}\end{array}$ & $\begin{array}{l}\mathrm{P}+\mathrm{CT} \text { versus } \mathrm{CT} \text {, No-Sq. } \\
\text { (All comers) }\end{array}$ & 616 & $\begin{array}{l}22.0 \text { versus } 10.6 \\
0.56(0.46-0.69)\end{array}$ & $\begin{array}{c}0.51 \\
(0.36-0.71)\end{array}$ & $\begin{array}{c}0.66 \\
(0.46-0.96)\end{array}$ & $\begin{array}{c}0.59 \\
(0.40-0.86)\end{array}$ & $\begin{array}{c}72 \% \text { versus } \\
67 \%\end{array}$ & $36 \%$ versus $17 \%$ \\
\hline $\begin{array}{l}\text { KEYNOTE } 407 \\
{[26]^{\#, 9}}\end{array}$ & $\begin{array}{c}\mathrm{P}+\mathrm{CT} \text { versus } \mathrm{CT} \text {, } \mathrm{Sq} . \text { (All } \\
\text { comers) }\end{array}$ & 558 & $\begin{array}{l}17.1 \text { versus } 11.6 \\
0.71(0.58-0.88)\end{array}$ & $\begin{array}{c}0.79 \\
(0.56-1.11)^{f}\end{array}$ & $\begin{array}{c}0.59 \\
(0.42-0.84)^{f}\end{array}$ & $\begin{array}{c}0.79 \\
(0.52-1.21)^{f}\end{array}$ & $\begin{array}{c}74 \% \text { versus } \\
70 \%\end{array}$ & $27 \%$ versus $13 \%$ \\
\hline IMpower 131 [31] & $\begin{array}{c}\mathrm{A}+\mathrm{CT} \text { versus } \mathrm{CT} \text {, Sq. (All } \\
\text { comers) }\end{array}$ & 1021 & $\begin{array}{l}14.2 \text { versus } 13.5 \\
0.88(0.73-1.05)\end{array}$ & $\begin{array}{c}0.87 \\
(0.67-1.13)\end{array}$ & $\begin{array}{c}1.08 \\
(0.81-1.45)\end{array}$ & $\begin{array}{c}0.48 \\
(0.29-0.81)\end{array}$ & $\begin{array}{c}\sim 75 \% \\
\text { versus } 70 \%\end{array}$ & $\sim 30 \%$ versus $17 \%$ \\
\hline IMpower $130[22]^{\#, \text { I }}$ & $\begin{array}{c}\mathrm{A}+\mathrm{CT} \text { versus } \mathrm{CT} \text {, No-Sq. } \\
\text { (All comers) }\end{array}$ & 724 & $\begin{array}{l}18.6 \text { versus } 13.9 \\
0.79(0.64-0.98)\end{array}$ & $\begin{array}{c}0.81 \\
(0.61-1.08)^{f}\end{array}$ & $\begin{array}{c}0.70 \\
(0.45-1.08)^{f}\end{array}$ & $\begin{array}{c}0.84 \\
(0.51-1.39)^{f}\end{array}$ & $\begin{array}{c}75 \% \text { versus } \\
61 \%\end{array}$ & $26 \%$ versus $22 \%$ \\
\hline $\begin{array}{l}\text { IMpower } 150[23 \text {, } \\
24]^{\#, 4}\end{array}$ & $\begin{array}{l}\mathrm{ABCP} \text { versus } \mathrm{BCP}, \text { No-Sq. } \\
\text { (All comers) }^{+}\end{array}$ & 696 & $\begin{array}{l}19.2 \text { versus } 14.7 \\
0.78(0.69-0.96)\end{array}$ & $\begin{array}{c}0.82 \\
(0.62-1.08)^{f}\end{array}$ & $\begin{array}{c}0.80 \\
(0.55-1.15)^{f}\end{array}$ & $\begin{array}{c}0.70 \\
(0.43-1.13)^{f}\end{array}$ & $\begin{array}{c}60 \% \text { versus } \\
51 \%\end{array}$ & $34 \%$ versus $25 \%$ \\
\hline IMpower 132 [30] & $\begin{array}{l}\mathrm{A}+\mathrm{CT} \text { versus } \mathrm{CT}, \text { No-Sq. } \\
\text { (All comers) }\end{array}$ & 578 & $\begin{array}{l}17.5 \text { versus } 13.6 \\
0.86(0.71-1.06)\end{array}$ & Not reported & Not reported & Not reported & & \\
\hline $\begin{array}{l}\text { ORIENT-11 } \\
\text { [25] }\end{array}$ & $\begin{array}{l}\mathrm{S}+\mathrm{CT} \text { versus } \mathrm{CT} \text { No-Sq. } \\
\text { (All comers). Asian }\end{array}$ & 397 & $\begin{array}{l}\text { NR versus NR } \\
0.61(0.40-0.93)\end{array}$ & Not reported & Not reported & Not reported & $\begin{array}{c}62 \% \text { versus } \\
59 \%\end{array}$ & $6 \%$ versus $8.4 \%$ \\
\hline ORIENT-12 [27] & $\begin{array}{l}\text { S+CG versus CG Sq. (All } \\
\text { comers). Asian }\end{array}$ & 357 & $\begin{array}{c}\text { NR versus NR } \\
0.57(0.35-0.91)\end{array}$ & Not reported & Not reported & Not reported & $\begin{array}{c}87 \% \text { versus } \\
83 \%\end{array}$ & $10 \%$ versus $8 \%$ \\
\hline
\end{tabular}

N: Nivolumab; I: Ipilimumab; P: Pembrolizumab; A: Atezolizumab; B: Bevacizumab; C: Cemiplimab; D: Durvalumab; S: Sintilimab; T: Tremelimumab; CP: carboplatin and paclitaxel; CT: chemotherapy; CG: Cisplatin/Carboplatin and Gemcitabine; AE: adverse events; NR: not reached; Sq: Squamous. \#: European Medicines Agency approval; `: US Food and Drug Administration approval; +: Table only includes data from arm B versus C of IMpower150 trial (wild-type, intention to treat); ${ }^{\S}$ : OS in PD-L1 $\geqslant 1 \%$; ${ }^{f}$ : exploratory analysis.

chemotherapy in tumours with PD-L1 expression $\geqslant 50 \%$ [18] (table 1). According to all these data, in first-line setting, the EMA approved pembrolizumab in high PD-L1 expression tumours, whereas the FDA approved pembrolizumab in PD-L1 $\geqslant 1 \%$ tumours and atezolizumab in high PD-L1 expression tumours. Likewise, the combination of ICIs has reported survival improvement compared with first-line chemotherapy. In the CheckMate 227, part 1 trial [19, 20], the combination of nivolumab plus ipilimumab achieved the primary endpoint reporting a survival benefit in PD-L1 positive tumours, with a 3-year OS of $33 \%$ with nivolumab plus ipilimumab and $22 \%$ with chemotherapy. In an exploratory analysis, the survival benefit occurred for both PD-L1 $\geqslant 1 \%$ (HR 0.76, 95\% CI 0.67-0.93) and in PD-L1<1\% (HR 0.64, 95\% CI $0.51-0.81$ ) populations [19]. However, in the PD-L1 $\geqslant 1 \%$ population the survival benefit seems mainly driven again by tumours with high PD-L1 expression (HR 0.70, 95\% CI: 0.55-0.90 in PD-L1 $\geqslant 50 \%$, whereas, HR 0.94, 95\% CI: 0.73-1.12 in PD-L1 1-49\%). Despite these limitations, the FDA approved this combination in May 2020 (table 1). Based on this data, the FDA approved nivolumab plus ipilimumab in first-line setting in PD-L1 $\geqslant 1 \%$ tumours. Of note, an exploratory landmark analysis from the CheckMate 227 trial reported that among patients with PD-L1 $1 \%$, 70\% of responders at 6 months in the nivolumab plus ipilimumab arm were alive 3 years later compared with $29 \%$ in the chemotherapy arm, whereas, there were no differences in patients achieving stable disease (39\% and $34 \%$, respectively), reinforcing that achieving a response on ICI is a marker for prolonged OS.

Altogether, these results suggest that ICI is an appropriate strategy for tumours highly dependent of immune pathway, with a grade $\geqslant 3$ adverse events rate ranging from $17 \%$ to $30 \%$, as well as discontinuation rate of $\sim 12 \%$. However, when we analyse the overall survival benefit, we must take into account other parameters such as the rate of subsequent immunotherapy strategies in the control arm the time of progression. Although, this rate was 70\% in the CheckMate 227 [19], KEYNOTE 024 [35] and EMPOWER-Lung 1 [18] 
trials, it was only of 29\% in the IMpower110 trial [34], whereas crossover was not allowed in the KEYNOTE 042 trial, with only 20\% of patients receiving ICI at progression in the control arm [36]. Indeed, only in pembrolizumab trials the efficacy of the drug according to PD-L1 strata was a primary endpoint [16, 35], whereas it was exploratory in the CheckMate227 trial [20]. Although ICI as monotherapy or in combination with other ICI seems appropriate for tumours with high PD-L1 expression, the benefit with these strategies in tumours with intermediate PD-L1 expression seems more limited.

\section{PD-L1 and chemo-immunotherapy combinations in NSCLC}

In clinical trials that assess the role of upfront ICI in patients with PD-L1 expression $\geqslant 1 \%[16,17,19]$ exist a phenomena where the survival curves cross at the beginning of the ICI treatment. This could suggest that a proportion of patients do not derive benefit of ICI therapy regardless of being selected for a potential predictive biomarker such as PD-L1 expression. With the aim to overcome this situation, and to take advantage of the synergic activity of cytotoxic and immunotherapy agents, different clinical trials have assessed the role of the combination of ICI plus chemotherapy (table 1). Recently it has been reported that risk of hyperprogressive disease occur in up to $16 \%$ of PD-L1 $150 \%$ NSCLC tumours treated with upfront pembrolizumab, but it is uncommon $(\sim 6 \%)$ in patients treated with chemo-immunotherapy strategy [37].

In non-squamous histology, the KEYNOTE-189 reported survival benefit in all PD-L1 strata (table 1) [21], whereas the IMpower150 trial [23, 24] reported a survival benefit with the combination of atezolizumab and bevacizumab plus chemotherapy compared with chemotherapy plus bevacizumab, including patients with liver metastases and with oncogenic addicted tumours (EGFR or ALK-positive). Although the IMpower130 trial [22] reported survival benefit with atezolizumab plus chemotherapy compared with chemotherapy alone, the benefit was only restricted to wild-type population and patients without liver metastases, suggesting a potential role of adding bevacizumab in these subsets of patients. However, a retrospective and exploratory analysis from KEYNOTE-189 trial suggested that pembrolizumab and chemotherapy is an optimal strategy even in patients with liver metastases [38]. Finally, in the phase 3 ORIENT-11 trial enrolling Asian non-squamous advanced NSCLC patients, the combination of sintilimab (an anti-PD1) and platinum pemetrexed improved the response rate, PFS in all PD-L1 strata and overall survival compared with chemotherapy alone [25].

Despite these clinically meaningful results, others trials have not reported survival improvement with the combination of ICI plus chemotherapy such as the IMpower132 [30] or the IMpower131 in squamous histology [31] (table 1). Likewise, the CheckMate 227 part 2 trial did not meet the primary endpoint of survival benefit with the combination of nivolumab plus chemotherapy compared with chemotherapy in non-squamous histology (18.8 months versus. 15.6 months, HR 0.86, 95\% CI: 0.69-1.08; p=0.1859), although in the exploratory analysis a survival benefit was observed with the combination in PD-L1 $\geqslant 50 \%$ (HR 0.56) [39].

Other clinical trials have explored the combination of ICI plus chemotherapy such as the CheckMate 9LA trial [28] that added two cycles of platinum-based chemotherapy at the beginning of the combination of nivolumab and ipilimumab in advanced NSCLC patients not selected for PD-L1 status. With a median follow-up of 13 months, the trial achieved the survival primary endpoint with the experimental arm, and this benefit occurred regardless of PD-L1 status (table 1) or histology subtype (HR 0.69, 95\% CI: 0.550.87 in non-squamous, and HR 0.62, 95\%CI $0.45-0.86$ in squamous histology). Despite this intensive treatment, the incidence of grade $\geqslant 3$ adverse events were similar between experimental and control arm (47\% versus. $38 \%$ ), with slightly higher discontinuation rate in the experimental arm (16\% versus. $5 \%$ ). The FDA and the EMA approved this strategy in first-line setting in May 2020 and September 2020, respectively. As contrary, the CCTG BR.34 trial did not report survival advantage with durvalumab plus tremelimumab and computed tomography (according to histologic subtype) compared with durvalumab and tremelimumab alone [40]. In contrast, a recent press release reported that the ongoing phase III POSEIDON trial (NCT03164616) evaluating durvalumab plus chemotherapy with or without tremelimumab or chemotherapy alone in unselected NSCLC patients achieved the co-primary PFS endpoint according to independent review, with overall survival data expected by April 2021. This trial may endorse the role of four-drug combination in the first-line setting.

One of the major clinical questions is the optimal treatment strategy in tumours with high PD-L1 expression, monotherapy or combination, as hazard ratio for overall survival in this subgroup of tumours is similar regardless the treatment strategy (table 1). However, differences exist between trials, as the follow-up is longer and crossover is higher in the KEYNOTE-024 trial [33] (5-years and 66\%) than in KEYNOTE-189 trial (19 months and 55\%) [41] or CheckMate 9LA trial [28] (12.7 months and 34\%). Likewise, despite similar efficacy, the toxicity profile is higher with combination strategies, and the 
economic impact probably is not the same. Some clinical parameters may help to make treatment decisions about the most suitable strategy in high PD-L1 expression tumours. Although, some studies did not report association between the radiographic tumour burden and efficacy of ICI in NSCLC [42], others did [43-45], and may suggest that in case of high tumour burden, ICI might need a chemotherapy boost regardless of high PD-L1 expression. The EA5163/S1709 phase III INSIGNA trial assesses whether induction with pembrolizumab is superior to pemetrexed and platinum plus pembrolizumab in advanced non-squamous lung cancer patients. The trial will stratify according to PD-L1 expression ( $\geqslant 50 \%$ versus. $1-49 \%$ ) and may help to elucidate the best strategy according to PD-L1 expression.

Focus on immunotherapy in PD-L1 negative NSCLC and squamous histology

Approximately one-third of NSCLC do not express PD-L1, but even in this subgroup, ICI combinations may improve survival (table 1) such as in the KEYNOTE 189 [21], CheckMate 9-LA [28] and the CheckMate 227 trial [19]. These data may suggest that the addition of anti-CTLA4 may enhance the immunogenicity of PD-L1 negative tumours, and a short course of chemotherapy along with ICI would be enough for obtaining the same survival benefit with a better toxicity profile than chemotherapy plus ICI [46]. Whether the chemotherapy is necessary in this subgroup remains to be elucidated, as the survival benefit in the CheckMate 227 trial in PD-L1 negative tumours was just an exploratory analysis. However, it is of relevance that one-third of patients treated with nivolumab plus ipilimumab in the CheckMate 227 trial are alive at three years regardless of PD-L1 status $(<1 \%$ or $\geqslant 1 \%)$ [19]. However, nivolumab plus ipilimumab is just approved by the FDA in PD-L1 $\geqslant 1 \%$ tumours.

Finally, with the aim to assess the role of ICI plus chemotherapy in PD-L1-negative tumours, a recent pooled analysis assessed this strategy in 428 PD-L1 negative tumours enrolled in three randomised trials (KEYNOTE-021G, KEYNOTE-189 and KEYNOTE-407). The analysis reported an overall survival improvement (HR 0.56; 95\% CI: 0.43-0.73) with pembrolizumab plus chemotherapy compared with chemotherapy alone, although $42 \%$ of patients in the control arm received an anti-PD-(L)1 at the time of progression. The overall survival benefit was observed in all subgroups, including squamous NSCLC (HR 0.61, 95\% CI: 0.38-0.96) [47].

Similarly in squamous histology, three studies have reported 5 months of median survival improvement with ICI compared with chemotherapy: the KEYNOTE 407 trial [26], testing the combination of pembrolizumab and chemotherapy (HR 0.71, 95\% CI: 0.58-0.88); the CheckMate 9LA trial [28] (HR 0.62, 95\% CI: 0.45-0.86), both approved by the FDA and the EMA; and the CheckMate 227 trial (HR 069, 95\% CI: 0.52-0.92) [20], only approved by the FDA. Of note, toxicity profile and discontinuations favour those trials without chemotherapy or only with a short course of chemotherapy along with ICI (table 1). However, neither CheckMate 9LA trial [28] nor CheckMate 227 trial [20] have reported the benefit in squamous subgroup according to PD-L1 strata. In the KEYNOTE 407 trial, the hazard ratio for overall survival was 0.67 (95\% CI: $0.51-0.87)$ in patients with PD-L1 $\geqslant 1 \%$ and 0.79 (95\% CI: 0.56-1.11) in patients with PD-L1 <1\%; however, the effect of PD-L1 expression in overall survival was a prespecified exploratory endpoint. Among PD-L1-positive patients, the hazard ratio for overall survival was 0.79 (95\% CI: $0.52-1.21$ ) among those with PD-L1 $\geqslant 50 \%$ and 0.59 (95\% CI: $0.42-0.84$ ) among those with PD-L1 $1-49 \%$ [26]. This lack of survival benefit in high PD-L1 expression tumour could be explained as 51\% of patients in control arm received ICI at the time of progression, 42\% receiving pembrolizumab, and the efficacy of pembrolizumab in second-line setting is higher in tumours with high PD-L1 expression [3]. More recently, in the ORIENT-12 trial performed in Asian patients with squamous advanced NSCLC, the combination of sintilimab plus platinum-gemcitabine chemotherapy improved the outcome (PFS, HR 0.53; $\mathrm{p}<0.001$ and OS, HR 0.57, p=0.017) compared with chemotherapy [27]. Finally, the IMpower 131 trial [31], testing atezolizumab plus chemotherapy in squamous NSCLC patients did not improve the overall survival compared with chemotherapy alone, except for the subgroup of patients with high PD-L1 expression. Similarly to non-squamous, it remains unresolved whether monotherapy or combination strategy is the most suitable in tumours with high PD-L1 expression. The efficacy and toxicity ratio and tumour burden may help for making treatment decisions.

\section{Tumour mutational burden as a predictive biomarker}

TMB is the total number of nonsynonymus, somatic mutations (Mut) identified per megabase (Mb) of the coding area in tumour genome. Although there is no consensus for standard measuring TMB, whole exome sequencing (WES) has been traditionally used for its evaluation. However, its implementation in clinical practice is challenging. Alternative comprehensive gene panels have been developed as alternative methods measuring the number of mutations through next-generation sequencing (NGS) approaches with good concordance with WES. However, there is a lack of harmonisation to convert TMB quantification across the different gene panels and a standard cut-off definition across cancer types or specific tumour 
types does not exist yet [48]. Recently, a new method to estimate human leukocyte antigen (HLA)-corrected TMB a modification, which considers the loss of heterozygosity of HLA from conventional TMB, was applied in two cohorts of patients treated with ICI. This new method classified better patients who get benefit of ICI and in the multivariable analysis, high HLA-corrected TMB correlated with survival, whereas conventional TMB did not, suggesting this new method as a predictive as well as prognostic factor that merits further evaluation [49].

The predictive role of TMB in NSCLC was initially observed in two independent cohorts reporting that an higher number of non-synonymous mutations in tumours correlated with improved outcome with ICI [50]. Likewise, an exploratory analysis from the CheckMate 026 trial nivolumab compared with chemotherapy in patients with high TMB (>243 Mut by WES) reported a higher response rate (47\% versus. 28\%) and longer PFS (9.7 months versus. 5.8 months, HR 0.62, 95\% CI: 0.38-1.00), with no differences in overall survival. The trial showed there was no significant association between TMB and PD-L1 expression, however, those patients with both predictive biomarkers (high TMB and high PD-L1) derived the most of nivolumab treatment compared with other subgroups [29]. This trial established the potential role of TMB for selecting patients for ICI treatment. The phase II CheckMate 568 trial established the TMB cut-off (assessed by FoundationOne CDx assay) associated with enhanced activity of upfront nivolumab plus ipilimumab, demonstrating the optimal classification performance of high TMB at $10 \mathrm{Mut} / \mathrm{Mb}$ [51]. Although, the phase III CheckMate 227 trial achieved the co-primary endpoint of longer PFS with nivolumab plus ipilimumab compared with chemotherapy in patients with high TMB (HR 0.58, 75\% CI 0.41-0.81) [52], the overall survival benefit (coprimary endpoint) occurred regardless of TMB cut-off assessed (high, $\geqslant 10$ Mut/Mb: HR 0.68, 95\% CI: 0.51-0.91; or low,<10 Mut/Mb: HR 0.75, 95\% CI: 0.590.94), thus questioning the predictive role for TMB as a biomarker for ICI. An exploratory analysis from KEYNOTE 042 trial, those tumours with high TMB ( $\geqslant 175$ Mut by WES, $44 \%$ of all TMB-evaluable population) were associated with improved clinical outcomes for pembrolizumab monotherapy in PD-L1-positive NSCLC patients [53]. As a contrary, no significant association was reported between TMB and efficacy of pembrolizumab or placebo plus platinum pemetrexed in the KEYNOTE 189 using the same cut-off point for defining the high TMB. Of note, the magnitude of overall survival benefit of pembrolizumab plus chemotherapy was similar in the TMB-high and TMB-low subgroups (HR 0.64 and HR 0.64, respectively) [54]. Although, in daily clinical practice the role of TMB in NSCLC for making treatment decisions is controversial, the FDA has recently approved pembrolizumab in tumours with TMB-high ( $\geqslant 10$ Mut/Mb) according to the retrospective analysis of KEYNOTE-158 trial (NCT02628067) assessing the role of pembrolizumab in metastatic TMB-high solid tumours [55]. However, the specific role of this strategy in NSCLC patients remains unknown, as this analysis did not include any cohort of NSCLC patients.

As an alternative to tissue, TMB has been also assessed in circulating tumoural DNA (ctDNA) from blood/ plasma (bTMB). In one retrospective study in NSCLC, bTMB was determined using a 394-gene panel and was compared to tissue TMB (FoundationOne CDx assay) and to the FoundationACT (FACT) dedicated to ctDNA assay (including only 62 genes). Out of 259 patients were evaluable for both bTMB and tissue TMB. Overall agreement and positive percent agreement (PPA) were $81.5 \%$ and $63.6 \%$ respectively when using the 394-gene panel for bTMB. However, when the FACT assay was compared to tissue TMB, PPA dropped to $17 \%$, suggesting a sufficiently sized panel is required to sensitively identify patients with high TMB. However, the performance on variant detection was similar when overlapping allele regions were compared: 93\% of variants were detected in both assays [56]. The prospective B-F1RST trial established the proof of concept the role of bTMB as predictive biomarker in first-line setting, reporting higher response rate (29\% versus. 4.4\%), longer PFS (5.0 versus. 3.5 months, HR $0.80 ; 0.54-1.18$ ) and overall survival (23.9 months versus. 13.4 months, HR 0.66; 0-40-1.10) with atezolizumab in tumours with high $(\geqslant 16 \mathrm{Mut} / \mathrm{Mb})$ versus low bTMB [57]. A confirmatory phase 3 study (BFAST, NCT03178552) is currently ongoing and recruiting patients, assessing the role of atezolizumab versus platinum-based chemotherapy in advanced NSCLC patients with high bTMB. In the MYSTIC trial, a pre-planned exploratory analysis examined survival according to bTMB, which could be determined in $72.4 \%$ of patients ( $\mathrm{n}=809$ ). For patients with a high bTMB ( $\geqslant 16 \mathrm{Mut} / \mathrm{Mb}, 39 \%$ of all patients in whom bTMB was assessed), the median overall survivals were 16.5, 11,0 and 10.5 months, for durvalumab plus tremelimumab, durvalumab monotherapy and platinum-based chemotherapy, respectively. The predictive value for survival of bTMB was only significant for the combination compared with chemotherapy (HR 0.62; 95\%CI: 0.45-0.86), but not for durvalumab monotherapy compared with chemotherapy (HR 0.80; 95\%CI: 0.59-1.07). Similarly, with a cut-off point of $\mathrm{bTMB} \geqslant 20 \mathrm{Mut} / \mathrm{Mb}$, survival improvement was achieved with the combination of durvalumab plus tremelimumab compared with chemotherapy (21.9 months versus 10.0 months; HR 0.49, 95\% CI: 0.32-0.74), but not with durvalumab compared with chemotherapy (12.6 months versus 10.0 months, HR 0.72, 95\% CI: 0.50-1.05). The phase III NEPTUNE trial (NCT02542293) determined 
the efficacy of the combination of durvalumab plus tremelimumab versus platinum-based chemotherapy in first-line setting of stage IV NSCLC patients. On June 6, 2019, the primary endpoint of this study changed from all patients to overall survival in patients with $b T M B \geqslant 20 \mathrm{Mut} / \mathrm{Mb}$, and a press release on August 21, 2019, reported that the combination ICI arm did not meet the primary overall survival endpoint compared with chemotherapy [58]. Therefore, the predictive biomarker role of TMB for the combination of durvalumab and tremelimumab remains a challenge in the absence of prospective validation for survival benefit. One main limitation of bTMB is that this test is accurate if the ctDNA levels are elevated. It has been established that ctDNA is related to the tumour burden. Thus, a failure of the bTMB might reflects a lower tumour burden, a predictive factor of sensitivity to ICI [59]. Indeed, in B-F1RST trial, the best benefit was seen in the patients with failed bTMB test.

Gene mutations and efficacy of immunotherapy in NSCLC

Specific gene mutations have been associated with resistance (STK11 and KEAP1) or sensitisation (ARID1A) to anti-PD-(L)1 monotherapy, and others have reported variable results. KRAS mutation occurs in $25-30 \%$ of lung adenocarcinomas, with KRAS G12C comprising $\sim 12 \%$ of cases. KRAS mutations are associated with high TMB and increased PD-L1 expression, and studies have reported variable results with ICI in NSCLC with KRAS mutations [60]. In an exploratory analysis from the KEYNOTE 042 trial [61], $23 \%$ of non-squamous NSCLC patients had a KRAS mutation ( $\mathrm{n}=301$, including $9.6 \%$ with KRAS G12C mutation). Pembrolizumab monotherapy versus chemotherapy alone was generally associated with improved clinical outcomes regardless of KRAS status, even among the 29 patients with a KRAS G12C mutation. Similarly, in KEYNOTE189 the benefit of pembrolizumab plus chemotherapy occurred regardless the occurrence of KRAS mutation, but KRAS status was only available for 89 patients enrolled in the trial [62]. STK11 (also called LKB1) and KEAP1 mutation occurs each mutation in $~ 17 \%$ of adenocarcinomas, respectively, and correlates with poor outcome with ICI or ICI plus chemotherapy [60, 63]. However, in other recent exploratory analysis from the KEYNOTE024 trial, STK11, KEAP1 and STK11/ KEAP1 mutations were present in $7.7 \%, 14.9 \%$ and $2.8 \%$ of patients and the presence of these mutations did not negatively impact in the survival benefit of pembrolizumab over chemotherapy. Patients with versus without STK11 mutation had lower PD-L1 expression but higher tissue TMB, whereas patients with versus without KEAP1 mutation had similar levels of PD-L1 expression but higher TMB [64]. Finally, in the IMpower150 trial, from the 920 mutation-evaluable patients, 25\%, 15\% and 16\% had KRAS, STK1 and KEAP1 mutations, respectively. Within KRAS mutation subgroup up to $45 \%$ of patients also had co-occurring mutations in STK11 or KEAP1. All these mutations were generally associated with higher TMB levels than wild-type tumours for these mutations, and efficacy of atezolizumab, bevacizumab and chemotherapy occurred regardless the occurrence of these mutations [65]. The role of these mutations in double immune blockade remains unknown and combination strategy of ICI plus chemotherapy instead of ICI monotherapy should be considered the current standard in this subset of lung cancer patients.

The assessment of these mutations in ctDNA were analysed in the MYSTIC trial. Among the mutation evaluable population ( $\mathrm{n}=943$ ), the incidence of mutations in STK11, KEAP1 and ARID1A were 16\%, 18\% and $12 \%$, respectively, and STK11 and KEAP1 were more prevalent in patients with non-squamous than squamous carcinoma. Shorter overall survival across all treatment arms were reported in patients with mutation in STK11 or KEAP1 compared with STK11 or KEAP1 wild-type, whereas patients with ARID1A mutation had a longer median overall survival than patients with ARID1A wild-type in the ICI combo arm, but not in the durvalumab arm compared with chemotherapy [66]. These data support STK11 and KEAP1 as prognostic and ARID1A as predictive biomarker, but they are exploratory and require further validation.

\section{Small cell lung cancer}

Immune status of small cell lung cancer and neuroendocrine tumour of the thorax

The initial revolutionising results observed with ICIs in NSCLC triggered the enthusiasm towards their application for improving the outcomes also of patients with advanced SCLC, characterised by dismal prognosis and the lack of relevant therapeutic improvements since decades. Despite previous failure of treatment strategies encompassing immune-directed drugs (namely the uselessness of adding CTLA-4 blockade to upfront chemotherapy) [67], some pathological elements of SCLC suggested its immunogenicity and the potential susceptibility to ICIs administration. Auto-immune neurological paraneoplastic syndromes (developing approximately in 5\% of the cases) negatively affect SCLC patients' prognosis and quality of life [68]. Nevertheless, the subclinical detection of Anti-Hu antibodies (present in 16\% of SCLC patients), recognising antigens expressed by neurons and SCLC, is associated with limited stage (versus extensive stage) and with better outcomes with chemotherapy, suggesting the immune system may contribute to control this aggressive disease [69]. On the other hand, still considering the challenges represented by evaluating its biology on mainly on small biopsies, SCLC is characterised by the abundance of tumour cells and necrosis, globally lacking an important immune infiltrate, a known prerogative for ICIs activity. 
Interestingly, the presence of an immune infiltrate correlates with survival in cohorts of resected thoracic neuroendocrine tumours, with an enrichment in SCLC [70, 71]. Of note, the large majority of evidence in this field has been obtained in SCLC, with some studies dealing with other neuroendocrine malignancies as well, namely large-cell neuroendocrine carcinoma (LCNEC) [71-74]. Given the recent deeper understanding of the biology of LCNEC, an up-regulation of immune-related pathways has been revealed in a specific subtype (type II LCNEC), characterised by a specific molecular background [75].

Tumour PD-L1 positivity was initially reported in more than 70\% of SCLC, correlated with limited disease (LD) and overall survival [76]. Nevertheless, following studies performed with diverse anti-PD-L1 clones, validated on NSCLC specimens as specific and reliable, scaled down the magnitude of PD-L1 expression in SCLC, especially with regard to tumour cells [73, 74, 77-79]. Moreover, as SCLC arise almost exclusively in patients with a relevant smoking history, TMB is globally high [80, 81], suggesting a potential benefit from ICIs. In spite of these elements, the results observed in clinical trials evaluating ICIs in extensive disease (ED) SCLC have provided new treatment standards for the clinical practice, but did not retrace the magnitude of benefit achieved in advanced NSCLC and not being possible to perform patients" selection due to the lack of potential predictive biomarkers. Summarising recent evidence, the addition of PD-L1 agents to first-line chemotherapy has been proven to be beneficial in activity and efficacy, without relevant toxicities issues, and represent the new standard of care $[4,5]$. Up to September 2020, both the FDA and the EMA approved regimens with platinum and etoposide chemotherapy with either atezolizumab (IMpower 133 trial) or durvalumab (CASPIAN trial). However, although the addition of PD-1 agents (pembrolizumab in KEYNOTE 604 trial) to chemotherapy reported a statistically significant improvement in PFS, the combination did not reach significant for the coprimary overall survival endpoint [82]. Based on disappointing overall survival results in several phase II/III studies were disappointing in evaluating PD-1/PD-L1 (with or without CTLA-4) inhibition in maintenance or later treatment lines (table 2) [4, 82-94], the initial approved by the FDA of anti-PD-1 blockade as a potential option in the third-line treatment of SCLC either with nivolumab or pembrolizuamb [95, 96] has been recently withdrawn.

Of note, in both treatment scenarios median values of survivals are scarcely representative of the benefit generated by ICIs, as usually see with immunotherapy trials [97]. On the other hand, long-term estimations, still not optimistic as the one observed in NSCLC patients, indicates that a minority of patients may derive prolonged benefit from ICIs administration. Whether this benefit is really related to ICI efficacy or patients" selection bias remains unknown. From this point of view, the identification of immune-related markers able to predict extended survival is crucial for several reasons: 1) to limit the administration of ICIs-containing regimens to patients more suitable of benefitting; 2) to boost immune strategies in these patients, in order to amplify the long-term outcomes; 3) to address other patients to novel therapies to be tested.

\section{$P D-L 1$ expression and ICIs in SCLC}

The evaluation of PD-L1 expression has been rarely considered mandatory to include SCLC patients in ICIs clinical trials, likely due to its difficult assessment in small, necrotic biopsies, the lack of IHC harmonisation and definition of positivity, as well as to the initial proofs questioning the actual prognostic and predictive role of PD-L1 expression in this setting. All the analyses performed within clinical trials were indeed exploratory.

Assuming the combination of chemotherapy with anti-PD-1/PD-L1 agent the new standard of care in first-line SCLC, the benefit generated by the addition of ICIs in IMpower133 and KEYNOTE-604 was observed regardless of PD-L1 expression (table 3) [4, 82]. In both the trials, PD-L1 was assessed in tumour and immune cells, and in KEYNOTE-604 integrated into the combined positive score (CPS), the number of PD-L1-positive cells (tumour cells, lymphocytes, macrophages) divided by the number of viable tumour cells, multiplied by 100 . Of note, if considering separately the cellular counterparts, PD-L1 staining in was estimated negative (i.e. present in $<1 \%$ of the populations) in $94 \%$ and approximately $50 \%$ of tumour and immune cell, respectively. In addition to the data reported in table 3, in IMpower133 any differential effect was seen when putting the cut-off of PD-L1 positivity at $\geqslant 5 \%$ neither [83]. Moving to the maintenance treatment in the phase II pembrolizumab study, only three out of 30 specimens were considered positive on the tumour compartment, and it was suggested that the detection of PD-L1 expression at the interface between tumour and stroma may be associated with better prognosis [86] (table 3). When assessing PD-L1 expression on tumour cells only, response rates did not differ between subgroups in patients exposed to nivolumab \pm ipilimumab as the second or later treatment line [96, 98]. Albeit lacking statistical analyses, better activity and efficacy outcomes were observed in SCLC patients receiving pembrolizumab in the case of PD-L1 positive tumours [90, 95] (table 3). In the phase II trial of atezolizumab 
TABLE 2 Activity, efficacy and toxicity outcomes reported in trials evaluating immune checkpoint inhibitors in small cell lung cancer

\begin{tabular}{|c|c|c|c|c|c|c|}
\hline Trial & $\mathrm{N}$ & Drugs & ORR & $\begin{array}{l}\text { Median PFS } \\
\text { HR }(95 \% \mathrm{CI})\end{array}$ & $\begin{array}{l}\text { Median OS } \\
\text { HR }(95 \% \mathrm{CI})\end{array}$ & $\begin{array}{c}\text { Grade } \geqslant 3 \\
\text { AE (\%) }\end{array}$ \\
\hline \multicolumn{7}{|l|}{ First line } \\
\hline IMpower133 [4, 83] & 403 & $\begin{array}{c}\text { Atezolizumab+CT versus } \\
\text { Placebo+CT }\end{array}$ & $\begin{array}{c}60 \% \text { versus } \\
64 \%\end{array}$ & $\begin{array}{c}5.2 \text { versus } \\
4.3 \text { months } \\
0.77(0.62-0.96)\end{array}$ & $\begin{array}{c}12.3 \text { versus } \\
10.3 \text { months } \\
0.76(0.60-0.95)\end{array}$ & $\begin{array}{l}68.2 \text { versus } \\
64.8\end{array}$ \\
\hline CASPIAN $[5,6]$ & 537 & Durvalumab+CT versus $\mathrm{CT}$ & $\begin{array}{c}67.9 \% \text { versus } \\
57.6 \%\end{array}$ & $\begin{array}{c}5.1 \text { versus } \\
5.4 \text { months } \\
0.78(0.64-0.93)\end{array}$ & $\begin{array}{c}13 \text { versus } \\
10.3 \text { months } \\
0.73(0.59-0.90)\end{array}$ & $\begin{array}{l}64.6 \text { versus } \\
63.6\end{array}$ \\
\hline KEYNOTE-604 [82] & 453 & $\begin{array}{c}\text { Pembrolizumab+CT versus } \\
\text { Placebo+CT }\end{array}$ & $\begin{array}{c}70.6 \% \text { versus } \\
61.8 \%\end{array}$ & $\begin{array}{c}4.8 \text { versus } \\
4.3 \text { months } \\
0.75(0.61-0.91)\end{array}$ & $\begin{array}{c}10.8 \text { versus } \\
9.7 \text { months } \\
0.80(0.64-0.98)^{\#}\end{array}$ & $\begin{array}{l}79.4 \text { versus } \\
77.6\end{array}$ \\
\hline ECOG-ACRIN EA516 [84] & 160 & Nivolumab+CT versus CT & $\begin{array}{c}52 \% \text { versus } \\
47 \%\end{array}$ & $\begin{array}{c}5.5 \text { versus } \\
4.6 \text { months } \\
0.65(0.46-0.91)\end{array}$ & $\begin{array}{c}11.3 \text { versus } \\
8.5 \text { months } \\
0.67(0.46-0.98)\end{array}$ & 77 versus 62 \\
\hline \multicolumn{7}{|l|}{ Maintenance } \\
\hline CheckMate 451 [85] & 834 & $\begin{array}{c}\text { Nivolumab+Ipilimumab versus } \\
\text { Placebo }\end{array}$ & NR & $\begin{array}{c}1.7 \text { versus } \\
1.4 \text { months } \\
0.72(0.6-0.87)\end{array}$ & $\begin{array}{c}9.2 \text { versus } \\
9.6 \text { months } \\
0.92(0.75-1.12)\end{array}$ & 54 versus 8 \\
\hline NCT02359019 [86] & 45 & Pembrolizumab & $11.1 \%$ & 1.4 months & 9.6 months & NA \\
\hline \multicolumn{7}{|l|}{$\geqslant$ Second line } \\
\hline CheckMate 33 [87] & 569 & Nivolumab versus CT & $\begin{array}{c}14 \% \text { versus } \\
17 \%\end{array}$ & $\begin{array}{c}1.4 \text { versus } \\
3.8 \text { months } \\
1.41(1.18-1.69)\end{array}$ & $\begin{array}{c}7.5 \text { versus } \\
8.4 \text { months } \\
0.86(0.72-1.04)\end{array}$ & 15 versus 74 \\
\hline IFCT-1603 [88] & 73 & Atezolizumab versus CT & $\begin{array}{c}2.3 \text { versus } \\
10 \%\end{array}$ & $\begin{array}{c}1.4 \text { versus } \\
4.3 \text { months } \\
2.26(1.3-3.93)\end{array}$ & $\begin{array}{c}9.5 \text { versus } \\
8.7 \text { months } \\
0.84(0.45-1.58)\end{array}$ & NA \\
\hline PCD4989 g [89] & 17 & Atezolizumab & $17.6 \%$ & 2.9 months ${ }^{\bullet}$ & 5.9 months & 29.4 \\
\hline $\begin{array}{l}\text { KEYNOTE-158 [90] } \\
\geqslant \text { third line }\end{array}$ & 107 & Pembrolizumab & $18.7 \%$ & 2 months & 9.1 months & 12 \\
\hline KEYNOTE-028 [91] & 24 & Pembrolizumab & $33.3 \%$ & 1.9 months & 9.7 months & 8.3 \\
\hline $\begin{array}{l}\text { CheckMate } 032 \text { [92] } \\
\text { (non-randomised cohort) }\end{array}$ & 98 & $\begin{array}{c}\text { Nivolumab } \\
\text { Nivolumab+Ipilimumab }\end{array}$ & $\begin{array}{l}11 \% \\
23 \%\end{array}$ & $\begin{array}{l}\text { NR } \\
\text { NR }\end{array}$ & $\begin{array}{l}4.1 \text { months } \\
6 \text { months }\end{array}$ & NA \\
\hline $\begin{array}{l}\text { CheckMate } 032[93] \\
\text { (randomised cohort) } \\
\text { nivolumab } \geqslant \text { third line }\end{array}$ & $\begin{array}{c}147 \\
96\end{array}$ & $\begin{array}{l}\text { Nivolumab versus } \\
\text { Nivolumab+Ipilimumab }\end{array}$ & $\begin{array}{c}11.6 \% \text { versus } \\
21.9 \%\end{array}$ & $\begin{array}{l}1.4 \text { months } \\
1.5 \text { months }\end{array}$ & $\begin{array}{c}5.7 \text { months } \\
4.7 \text { months } \\
1.05(0.74-1.47)\end{array}$ & $\begin{array}{l}12.9 \text { versus } \\
37.5\end{array}$ \\
\hline BALTIC [94] & 21 & Durvalumab+Tremelimumab & $9.5 \%$ & 1.9 months & 6 months & 48 \\
\hline
\end{tabular}

N: Number of patients; ORR: Objective response rate; PFS: Progression-free survival; HR: Hazard ratio; 95\% Cl: 95\% confidence interval; OS: Overall survival; AE: adverse events; CT: Chemotherapy; NR: Not reported; NA: Not available. \#: Statistically non-significant; ": according to immune-related response criteria (irRC).

in the second-line setting of SCLC, PD-L1 expression failed to show a prognostic role, as patients receiving the PD-L1 agent were gathered with the chemotherapy-treated ones before assessing the outcomes according to PD-L1 expression in either tumour or immune cells [88].

Albeit some hints may suggest better outcomes on ICIs in pretreated, PD-L1 positive patients, evidence is far not robust to define PD-L1 as a good biomarker in SCLC, even more considering that no sign of differential benefit has been showed with chemotherapy-ICIs combinations.

\section{Tumour mutational burden and ICIS in SCLC}

The strict aetiopathogenic link between smoking exposure and SCLC accounts for the high number of somatic mutations characteristic of SCLC $[80,81]$. As seen in NSLC, no correlation between the presence of high TMB and PD-L1 expression have been observed [83, 92].

In the setting of exploratory analyses within ICIs clinical trials and retrospective experiences, differential outcomes have been observed in SCLC patients when categorised according to TMB, quantified in tumour tissue or in circulating tumour DNA (ctDNA) (table 4) [4, 83, 90, 92, 99]. In the pretreated setting, anti-PD-1 \pm anti-CTLA-4 treatments engendered the better results, both in terms of activity and efficacy, in the case of high TMB. Moving to first-line administration of chemotherapy \pm atezolizumab in the Impower133 trial, the benefits obtained in PFS and overall survival adding the anti-PD-L1 agent were 
TABLE 3 Outcomes in small cell lung cancer (extensive stage) studies with immune checkpoint inhibitors, according to PD-L1 status

\begin{tabular}{|c|c|c|c|c|c|c|c|c|}
\hline Trial & \multicolumn{2}{|c|}{ IMpower133 $[4,83]$} & \multicolumn{2}{|c|}{ KEYNOTE-604 [82] } & \multicolumn{2}{|c|}{$\begin{array}{l}\text { Pembrolizumab } \\
\text { maintenance [86] }\end{array}$} & \multicolumn{2}{|c|}{ KEYNOTE-158 [90] } \\
\hline Study phase & \multicolumn{2}{|c|}{ III } & \multicolumn{2}{|c|}{ III } & \multicolumn{2}{|c|}{ II } & \multicolumn{2}{|c|}{ II } \\
\hline Setting & \multicolumn{2}{|c|}{ First-line } & \multicolumn{2}{|c|}{ First-line } & \multicolumn{2}{|c|}{ Maintenance } & \multicolumn{2}{|c|}{$\geqslant 2$ nd line } \\
\hline Treatment & \multicolumn{2}{|c|}{$\begin{array}{c}\text { Carboplatin+etoposide } \pm \\
\text { atezolizumab }\end{array}$} & \multicolumn{2}{|c|}{$\begin{array}{c}\text { Platinum salt+etoposide } \pm \\
\text { pembrolizumab }\end{array}$} & \multicolumn{2}{|c|}{ Pembrolizumab } & \multicolumn{2}{|c|}{ Pembrolizumab } \\
\hline Total patients & \multicolumn{2}{|c|}{403} & \multicolumn{2}{|c|}{453} & \multicolumn{2}{|c|}{45} & \multicolumn{2}{|c|}{107} \\
\hline PD-L1 evaluated patients & \multicolumn{2}{|c|}{137} & \multicolumn{2}{|c|}{360} & \multicolumn{2}{|c|}{20} & \multicolumn{2}{|c|}{65} \\
\hline PD-L1 IHC & \multicolumn{2}{|c|}{ SP263 } & \multicolumn{2}{|c|}{$22 \mathrm{C} 3$} & \multicolumn{2}{|c|}{$22 C 3$} & \multicolumn{2}{|c|}{$22 \mathrm{C} 3$} \\
\hline \multirow[t]{3}{*}{ PD-L1 status } & \multicolumn{2}{|c|}{ TC or IC } & \multicolumn{2}{|c|}{ CPS } & \multicolumn{2}{|c|}{ Stromal interface } & \multicolumn{2}{|c|}{ CPS } \\
\hline & $<1 \%$ & $\geqslant 1 \%$ & $<1 \%$ & $\geqslant 1 \%$ & Negative & Positive & $<1 \%$ & $\geqslant 1 \%$ \\
\hline & 65 & 72 & 175 & 185 & 12 & 8 & 50 & 15 \\
\hline \multirow{6}{*}{$\begin{array}{l}\text { PFS data according to PD-L1 } \\
\text { status }\end{array}$} & & & HR & $\mathbf{R}$ & mPFS & lonths) & mPFS & onths) \\
\hline & $\begin{array}{c}0.51 \\
(0.30-0.89)\end{array}$ & $\begin{array}{c}0.87 \\
(0.5-1.49)\end{array}$ & $\begin{array}{c}0.80 \\
(0.58-1.11)\end{array}$ & $0.84(0.60-1.18)$ & $\begin{array}{c}1.3 \\
(0.6-2.5)\end{array}$ & $\begin{array}{c}6.5 \\
(1.1-12.8)\end{array}$ & $\begin{array}{c}1.9 \\
(1.6-2.0)\end{array}$ & $\begin{array}{c}2.1 \\
(2.0-8.1)\end{array}$ \\
\hline & & & & & & & 6-mo & h PFS \\
\hline & & & & & & & $14.3 \%$ & $38.9 \%$ \\
\hline & & & & & & & $12-\mathrm{m}$ & h PFS \\
\hline & & & & & & & $8.2 \%$ & $28.5 \%$ \\
\hline OS data according to PD-L1 & NA & NA & $0.73(0.54-1.01)$ & 0.68 & mos & onths) & mos & onths) \\
\hline status & & & & $(0.49-0.94)$ & $\begin{array}{c}7.6 \\
(2.0-12.7)\end{array}$ & $\begin{array}{c}12.8 \\
(1.1-17.6)\end{array}$ & $\begin{array}{c}5.9 \\
(3.3-10.1)\end{array}$ & $\begin{array}{c}14.9 \\
(5.6-\mathrm{NR})\end{array}$ \\
\hline & & & & & & & 6-mo & is os \\
\hline & & & & & & & $48.3 \%$ & $66 \%$ \\
\hline & & & & & & & $12-\mathrm{mc}$ & hs OS \\
\hline & & & & & & & $30.7 \%$ & $53.1 \%$ \\
\hline
\end{tabular}

Data between parenthesis indicate 95\% confidence intervals. IHC: immunohistochemistry; mPFS: median progression-free survival; mOS: median overall survival; OS: overall survival; TC: tumour cells; IC: immune cells; HR: hazard ratio; NA: not available; CPS: combined positive score.

observed regardless of ctDNA TMB (both at the cut-off of 10 and 16 mut/Mb), thus denying its potential predictive role in this new standard of care [83]. In light of the results of KEYNOTE-158 trial including SCLC ( $\mathrm{n}=75$, including 34 TMB-high tumours) and other malignancies, the FDA has provided a "pan-cancer" approval of pembrolizumab in the case of tumour TMB $\geqslant 10$ mut/Mb. There is still no formal, prospective proof that the patients experiencing long-term disease control to nivolumab or pembrolizumab, when administered as third or later line, are the ones whose tumous have high TMB levels. Nevertheless, TMB evaluation in this setting may help to address patients towards ICIs treatment, given their recent approval in this setting too.

\section{Malignant pleural mesothelioma}

\section{The immune context of malignant pleural mesothelioma}

The close epidemiological relationship asbestos exposure, implying a role of the inflammation in MPM pathogenesis, suggested MPM as a candidate for immune checkpoint blockade. In addition, besides its low mutational burden [100], PD-L1 expression is detected in approximately $20 \%-40 \%$ of MPM according to different techniques. Nevertheless, after the first encouraging evidence of the potential benefit of administering temelimumab in pretreated, advanced MPM patients [101, 102], CTLA-4 inhibition failed to show superiority compared to placebo in the phase IIb DETERMINE trial [103]. Thereafter, the identification of subgroups of patients who are most likely to drive benefit from ICI administration, in terms of specific histologies and PD-L1 expression, has become an element of central interest, as proven by recent results of clinical trials with PD-1/PD-L1 and CTLA-inhibitors. In previously treated MPM patients, the phase III PROMISE trial comparing pembrolizumab versus chemotherapy did not achieved the PFS primary endpoint nor the OS [104]. As contrary, the CheckMate 743 trial has shifted treatment paradigm in first-line setting in unresectable MPM [7]. In this trial the combination of nivolumab and ipilimumab significantly improved the median OS compared with platinum pemetrexed, reaching a 1- and 2 -year OS of $60 \%$ and $40 \%$, respectively. Based on these results, the FDA has approved in October 2020 the combination of nivolumab plus ipilimumab as the new standard of care in first-line setting. Another approach to booster the efficacy of ICI in MPM is the immune-chemotherapy approach. For instance, two single-arm phase II clinical trials (DREAM trial and PrE0505 trial) [105, 106] have reported that the addition of durvalumab to platinum-pemetrexed chemotherapy followed by durvalumab as a maintenance 
TABLE 4 Outcomes in small cell lung cancer (extensive stage) studies with immune checkpoint inhibitors, according to tumour mutational burden

\begin{tabular}{|c|c|c|c|c|c|c|c|c|c|c|c|c|}
\hline Trial [ref.] & \multicolumn{2}{|c|}{ IMpower $133[4,83]$} & \multicolumn{3}{|c|}{ CheckMate 032 [92] } & \multicolumn{3}{|c|}{ CheckMate 032 [92] } & \multicolumn{2}{|c|}{ KEYNOTE-158 [90] } & \multicolumn{2}{|c|}{ Ricciuti et al. [99] } \\
\hline Study phase & \multicolumn{2}{|r|}{ III } & \multicolumn{3}{|c|}{ I/II } & \multicolumn{3}{|c|}{$1 / I I$} & \multicolumn{2}{|c|}{ ॥ } & \multicolumn{2}{|c|}{ Retrospective series } \\
\hline Setting & \multicolumn{2}{|c|}{ First-line } & \multicolumn{3}{|c|}{$\geqslant 2$ nd line } & \multicolumn{3}{|c|}{$\geqslant 2$ nd line } & \multicolumn{2}{|c|}{$\geqslant 2$ nd line } & \multicolumn{2}{|c|}{$\geqslant 2$ nd line } \\
\hline Treatment & \multicolumn{2}{|c|}{$\begin{array}{l}\text { Carboplatin+etoposide } \pm \\
\text { atezolizumab }\end{array}$} & \multicolumn{3}{|c|}{ Nivolumab } & \multicolumn{3}{|c|}{ Nivolumab+ipilimumab } & \multicolumn{2}{|c|}{ Pembrolizumab } & \multicolumn{2}{|c|}{ PD-1 \pm CTLA-4 ICls } \\
\hline Total patients & \multicolumn{2}{|c|}{403} & \multicolumn{3}{|c|}{245} & \multicolumn{3}{|c|}{146} & \multicolumn{2}{|c|}{107} & \multicolumn{2}{|c|}{52} \\
\hline $\begin{array}{l}\text { Evaluated } \\
\text { patients }\end{array}$ & \multicolumn{2}{|r|}{346} & \multicolumn{3}{|c|}{133} & \multicolumn{3}{|c|}{78} & \multicolumn{2}{|c|}{75} & \multicolumn{2}{|c|}{52} \\
\hline Methods & \multirow{2}{*}{\multicolumn{2}{|c|}{$\begin{array}{c}\text { Targeted NGS } 394 \text { genes } \\
\text { Blood }\end{array}$}} & \multicolumn{3}{|c|}{ WES } & \multicolumn{3}{|c|}{ WES } & \multirow{2}{*}{\multicolumn{2}{|c|}{$\begin{array}{l}\text { Targeted NGS } 324 \text { genes } \\
\text { FoundationOne CDxTM } \\
\text { assay (v3.3) Tumour }\end{array}$}} & Targeted & 282 genes \\
\hline Material & & & & tumour and/or blood & & & tumour and/or blo & & & & $T$ & ur \\
\hline Patient groups & & Mb cut-off & & Mut tertiles & & & Mut tertiles & & & t-off & Mut/mb 5 & percentiles \\
\hline & $\geqslant 10$ & $\geqslant 16$ & $\begin{array}{l}\text { Low }(0- \\
142)\end{array}$ & $\begin{array}{l}\text { Medium (143- } \\
\quad 247)\end{array}$ & $\begin{array}{l}\text { High } \\
(\geqslant 248)\end{array}$ & $\begin{array}{l}\text { Low (0- } \\
142)\end{array}$ & $\begin{array}{l}\text { Medium (143- } \\
\quad 247)\end{array}$ & High $(\geqslant 248)$ & $<10$ & $\geqslant 10$ & $\begin{array}{l}\text { Low } \\
(\leqslant 9.68)\end{array}$ & $\underset{(>9.68)}{\text { High }}$ \\
\hline TMB & 212 & 80 & 42 & 44 & 47 & 27 & 25 & 26 & 41 & 34 & 26 & 26 \\
\hline ORR & & NA & $4.8 \%$ & $6.8 \%$ & $21.3 \%$ & $22.2 \%$ & $16 \%$ & $46.2 \%$ & $9.6 \%$ & $29.4 \%$ & $7.7 \%$ & 25 \\
\hline DCR & & NA & NA & NA & NA & NA & NA & NA & NA & NA & $19.2 \%$ & $57.7 \%$ \\
\hline mPFS (months) & $\begin{array}{c}<10: \mathrm{HR} \\
0.78 \\
(0.54-1.12) \\
\geqslant 10: \mathrm{HR} \\
0.69 \\
(0.52-0.93)\end{array}$ & $\begin{array}{c}<16: \text { HR } 0.73(0.56- \\
0.94) \\
\geqslant 16: \text { HR } 0.68 \\
(0.43-1.10)\end{array}$ & $\begin{array}{l}1.3(1.2- \\
1.4)\end{array}$ & $1.3(1.2-1.4)$ & $\begin{array}{l}1.4(1.3- \\
2.7)\end{array}$ & $\begin{array}{l}1.5(1.3- \\
2.7)\end{array}$ & $1.3(1.2-2.1)$ & $\begin{array}{l}7.8(1.8- \\
10.7)\end{array}$ & NA & NA & $\begin{array}{c}1.2(0.9- \\
1.8) \\
\text { HR } 0.37(0 .\end{array}$ & $\begin{array}{l}3.3(1.9-N R) \\
.69) p<0.01\end{array}$ \\
\hline 1-year PFS & & NA & NA & $3.1 \%$ & $21.2 \%$ & $6.2 \%$ & $8 \%$ & $30 \%$ & NA & NA & $7.7 \%$ & $29.9 \%$ \\
\hline mOS (months) & $\begin{array}{c}<10: \mathrm{HR} \\
0.73 \\
(0.49-1.08) \\
\geqslant 10: \mathrm{HR} \\
0.73 \\
(0.53-1.00)\end{array}$ & $\begin{array}{c}<16: \text { HR } 0.79(0.60- \\
1.04) \\
\geqslant 16: \text { HR } 0.58(0.34- \\
0.99)\end{array}$ & $\begin{array}{l}3.1(2.4- \\
6.8)\end{array}$ & $3.9(2.4-9.9)$ & $\begin{array}{l}5.4(2.8- \\
8.0)\end{array}$ & $\begin{array}{l}3.4(2.8- \\
7.3)\end{array}$ & $3.6(1.8-7.7)$ & $\begin{array}{c}22.0 \\
(8.2-\mathrm{NR})\end{array}$ & NA & NA & $\begin{array}{c}2.5(1.6- \\
6.8) \\
\text { HR } 0.38(0 .\end{array}$ & $\begin{array}{c}10.4 \\
(8.5-N R) \\
.77) p<0.01\end{array}$ \\
\hline 1-year OS & & NA & $22.1 \%$ & $26 \%$ & $35.2 \%$ & $23.4 \%$ & $19.6 \%$ & $62.4 \%$ & NA & NA & $19 \%$ & $48.4 \%$ \\
\hline
\end{tabular}

Data between parenthesis indicate 95\% confidence intervals. TMB: tumour mutational burden; ORR: objective response rate; DCR: Disease control rate; mPFS: Median progression-free survival; mOS: median overall survival; OS: overall survival; NGS: next-generation sequencing; Mut/Mb: mutations/megabase; NA: not available; HR: Hazard ratio; WES: Whole exome sequencing; ICls: Immune checkpoint inhibitors; NR: not reached. 
strategy achieves a median OS of 20 months and a 1-year and 2-year OS of $\sim 60 \%$ and $\sim 40 \%$, respectively. These data suggest a potential role of immune-chemotherapy strategy that must be confirmed in ongoing phase III trials (NCT04334759, NCT03762018, NCT02784171).

PD-L1 expression, mainly evaluated on surgical MPM samples using different IHC clones, has been detected both on tumour cells and immune-stromal phenotypes, still with the percentage of positive cases varying significantly across studies [107-111]. Nevertheless, the different experiences were concordant in defining non-epithelioid histologies (sarcomatoid and biphasic) more frequently characterised by PD-L1 positivity. In addition, in retrospective series the detection of PD-L1 was almost invariably associated with worst outcomes compared to MPM with no PD-L1 expression. The lack of predictive significance of PD-L1 status in randomised trials where ICI have been compared to chemotherapy (see next Section) makes this hypothesis more suitable than envisaging a true detrimental effect of PD-L1 expression in terms of a negative impact on the immune system.

The comprehension of the immune context of MPM at the micro-environmental level is a key prerogative to assess the potential role of ICIs, and to develop potential biomarkers. In several retrospective studies, the presence of a variety of immune and inflammatory phenotypes has been reported, whose differential proportion has been evaluated according to histology and PD-L1 status [112, 113]. UjIIE et al. [114] showed that a high CD163+ tumour-associated macrophages/CD8+ T lymphocytes ratio and a low CD163+/CD20+ B lymphocytes ratios were independent prognostic factors of worse and better survival outcomes, respectively. Non-epithelioid histologies have been more frequently characterised by higher CD8+ density and CD45RO+ memory cells, while epithelioid one has higher amounts of peritumoural CD4+ T and CD20+ B lymphocytes [115, 116]. PD-L1 expression has been shown to correlate with the presence of CD68+ macrophages [117], CD45+ immune cells, activated CD3+ $\mathrm{T}$ cells, proliferating CD8+ T cells and FOXP3+/CD4+ Treg lymphocytes [118]. Functional analyses revealed that CD8+ cells activity is mostly suppressed, especially if CD4+ Treg lymphocytes are concomitantly present [119]. CD8+ Abundance in CD8+ T lymphocytes and in CD68+ macrophages was associated with pathological features of aggressiveness, as well as PD-L1 positivity [115].

More recent studies focussing on the molecular landscape of MPM revealed features of potential ICI susceptibility. The negative immune checkpoint regulator VISTA (V-domain Ig suppressor of T-cell activation) become a potential therapeutic target since its mRNA expression (more frequent in epithelioid histology) emerged as strongly correlated with MPM phenotypes lacking mRNA signatures of epithelial-mesenchymal transition [120]. When analyzed through RNA sequencing, the co-expression of VISTA and of the proangiogenic gene VEGFR2 was associated with a better prognosis, compared to samples enriched in pro-angiogenic gene expression, with or without signatures of lymphocyte infiltration [121]. BAP1 (BRCA1 associated protein 1) is commonly inactivated by means of gene mutations or copy number loss in MPM, where BAP1 loss of function is reported in up to $60 \%$ of the cases [122-124]. Of interest, BAP1 haploinsufficiency strongly correlated with cytokine signalling an inflammatory tumour microenvironment [125].

Histology and PD-L1 expression as biomarkers in pleural mesothelioma patients receiving ICls The worst outcomes in pleural mesothelioma patients are observed in non-epithelioid histotypes (accounting for up to 25\% of MPM cases), due to their aggressiveness and chemo-resistance. Nevertheless, due the immune-pathological features (described in the previous Section), sarcomatoid and biphasic histologies were supposed being the more prone to immunotherapy action. Albeit some data sustained this hypothesis [116, 126, 127], non-epithelioid MPM cases included in clinical trials or retrospective series were too scant to drive any conclusion. Of major relevance, the combination of nivolumab and ipilimumab in MPM has been recently proven superior to first-line chemotherapy in terms of OS benefit. Albeit Checkmate 743 is formally positive in the intention-to-treat population (HR 0.74 (95\% CI 0.60-0.91); $\mathrm{p}=0.0020$ ), the subgroup analysis, powered by the stratification based on histology, clearly revealed a superiority of nivolumab and ipilimumab in non-epithelioid MPM only (HR 0.46 (95\% 0.31-0.68); HR 0.86 (95\% CI 0.69-1.08) for epithelioid cases) [7]. The outcomes of patients in ICI arms did not differ according to MPM histotypes, but the dismal results observed in non-epithelioid cases exposed to chemotherapy (table 5) [104-106, 126-135] account for the large superiority of nivolumab and ipilimumab treatment, that is likely to become the new standard of care for the first-line treatment of sarcomatoid and biphasic MPM.

The description of differential outcomes according to PD-L1 expression is present in the majority of clinical trials evaluating PD-1/PD-L1 \pm CTLA-4 inhibitors administration (table 6) [104-106, 126-130, 132-136]. PD-L1 IHC clones and cut-off utilised differed across studies. In non-randomised trials of ICI (or in the randomised, non-comparative one MAPS2), PD-L1 positive tumours (i.e. PD-L1 detected in $\geqslant 1 \%$ 


\begin{tabular}{|c|c|c|c|c|c|c|}
\hline Trial & $\mathrm{N}$ & Drugs & ORR & $\begin{array}{c}\text { Median PFS } \\
\text { months } \\
\text { HR }(95 \% \mathrm{CI})\end{array}$ & $\begin{array}{c}\text { Median OS } \\
\text { HR }(95 \% \mathrm{CI})\end{array}$ & $\begin{array}{c}\text { Grade } \\
\geqslant 3 \mathrm{AE} \\
(\%)\end{array}$ \\
\hline \multicolumn{7}{|l|}{ First line } \\
\hline DREAM [105] & 54 & Durvalumab+CT & $48 \%$ & 6.9 & 18.4 & NA \\
\hline PrE0505 [106] & 55 & Durvalumab+CT & $56.4 \%$ & 6.7 & 20.4 & 65.5 \\
\hline $\begin{array}{l}\text { CheckMate } 743 \\
\text { [7] }\end{array}$ & 605 & $\begin{array}{c}\text { Nivolumab } \\
\text { +Ipilimumab versus } \\
\text { CT }\end{array}$ & $\begin{array}{c}40 \% \\
\text { versus } \\
43 \%\end{array}$ & $\begin{array}{c}6.8 \text { versus } 7.2 \\
1.00(0.82- \\
1.21)\end{array}$ & $\begin{array}{c}18.1 \text { versus } \\
14.1 \text { months } \\
0.74(0.60-0.91)\end{array}$ & $\begin{array}{c}31 \text { versus } \\
32\end{array}$ \\
\hline \multicolumn{7}{|l|}{ First-second line } \\
\hline $\begin{array}{l}\text { NIBIT-MESO } \\
\text { [129] }\end{array}$ & 40 & $\begin{aligned} & \text { Durvalumab } \\
+ & \text { Tremelimumab }\end{aligned}$ & $28 \%$ & 5.7 & 16.6 months & 18 \\
\hline \multicolumn{7}{|l|}{ Second line } \\
\hline $\begin{array}{l}\text { PROMISE-meso } \\
{[104]}\end{array}$ & 144 & $\begin{array}{c}\text { Pembrolizumab } \\
\text { versus } \mathrm{CT}\end{array}$ & $\begin{array}{c}22 \% \\
\text { versus } \\
6 \%\end{array}$ & $\begin{array}{c}2.5 \text { versus } 3.4 \\
1.06(0.73- \\
1.53)\end{array}$ & $\begin{array}{c}10.7 \text { versus } \\
12.4 \text { months } \\
1.12(0.74-1.69)\end{array}$ & $\begin{array}{c}19.4 \\
\text { versus } \\
25.7\end{array}$ \\
\hline \multicolumn{7}{|l|}{ Second-third line } \\
\hline $\begin{array}{l}\text { NCT02399371 } \\
{[126]}\end{array}$ & 65 & Pembrolizumab & $22 \%$ & 4.1 & 11.5 months & NA \\
\hline $\begin{array}{l}\text { QUISPEL-JANSSEN } \\
{[130]}\end{array}$ & 34 & Nivolumab & $24 \%$ & 3.6 & NR & 29 \\
\hline MERIT [127] & 34 & Nivolumab & $29 \%$ & 6.1 & 17.3 months & 47 \\
\hline \multicolumn{7}{|l|}{$\geqslant$ Second line } \\
\hline $\begin{array}{l}\text { KEYNOTE-028 } \\
{[131]}\end{array}$ & 25 & Pembrolizumab & $20 \%$ & 5.4 & 18 months & 20 \\
\hline $\begin{array}{l}\text { JAVELIN Solid } \\
\text { Tumor [132] }\end{array}$ & 53 & Avelumab & $9.4 \%$ & 3.9 & NR & 9 \\
\hline INITIATE [133] & 34 & $\begin{array}{c}\text { Nivolumab } \\
\text { +Ipilimumab }\end{array}$ & $29 \%$ & 6.2 & NR & 38 \\
\hline IFCT-1501 & 62 & Nivolumab & $18.5 \%$ & 4 & 11.9 months & 15 \\
\hline $\begin{array}{l}\text { MAPS2 [134, } \\
135]\end{array}$ & 63 & $\begin{array}{c}\text { Nivolumab } \\
\text { +Ipilimumab }\end{array}$ & $25.9 \%$ & 5.6 & 15.9 months & 26 \\
\hline
\end{tabular}

$\mathrm{N}$ : number of patients; ORR: objective response rate; PFS: progression-free survival; HR: hazard ratio; 95\% CI: 95\% confidence interval; OS: overall survival; AE: adverse events; CT: chemotherapy; NR: not reported.

of tumour cells) derived better outcomes compared to negative diseases, and the differential benefit increase positioning the threshold of positivity at higher percentages of PD-L1 expression. In the INITIATE trial (nivolumab and ipilimumab in pretreated MPM patients) a higher score of PD-L1 expression on immune cells correlated with better response, clinical benefit and PFS, but not with OS [133]. Moreover in this study, as in the one reported by QuisPEL-JANSSEN et al. [130], re-biopsies were obtained after six weeks of treatment. In the two trials, conversions from PD-L1 positive-to-negative status (and vice versa) were observed, and in $10-20 \%$ of the cases no tumour cells were detectable, frequently in the presence with a dense immune infiltrate.

Nevertheless, when moving to randomised phase III trials, PD-L1 expression fails to show prognostic or predictive values. In the PROMISE-meso study no difference were detected according to subgroups identified through PD-L1 expression, after stratification by histological subtype, in PFS (PD-L1<1\%, HR 1.26 (95\% CI 0.56-2.83), p= 0.57; PD-L1 $\geqslant 1 \%$ HR 1.06 (95\% CI 0.63-1.80), $\mathrm{p}=0.82$ ) or OS (PD-L1<1\% HR 0.72 (95\% CI 0.26-2.00), p=0.53; PD-L1 $\geqslant 1 \%$ HR 1.47 (95\% CI 0.69-3.11), p=0.32) [104], not defining an optimal cut-off of PD-L1 expression to be used as a predictive biomarker. In the Checkmate 743 trial, PD-L1 was not a stratification factor and the trial was enriched in PD-L1 positive tumours (77\%), although PD-L1 expression did not correlate with outcome (HR for OS in PD-L1<1\% and PD-l1 $\geqslant 1 \% 0.94$ (95\% CI $0.62-1.40$ ) and 0.69 (95\% CI $0.55-0.87$ ), respectively), the magnitude of survival benefit was higher in PD-L1 positive tumours [7].

Immune checkpoint inhibitors in thymic epithelial tumours

Thymic epithelial tumours (TET) are rare (0.15-0.32 cases per million), and thymic carcinomas (TC) comprise approximately $10 \%-15 \%$ of TET. Platinum doublet therapy is the standard upfront treatment in 
TABLE 6 Outcomes in mesothelioma studies with immune checkpoint inhibitors, according to PD-L1 status

\begin{tabular}{|c|c|c|c|c|c|c|c|c|c|c|c|c|c|c|c|c|c|}
\hline \multirow{2}{*}{$\begin{array}{l}\text { Study } \\
\text { NCT02399371 [126] }\end{array}$} & \multirow{4}{*}{$\begin{array}{c}\text { Phase } \\
"\end{array}$} & \multirow{4}{*}{$\begin{array}{l}\text { Setting } \\
\begin{array}{c}2 n d / 3 r d \\
\text { line }\end{array}\end{array}$} & \multirow{4}{*}{$\begin{array}{c}\text { Treatment } \\
\text { Pembrolizumab }\end{array}$} & \multirow{4}{*}{$\begin{array}{c}\begin{array}{c}\text { Total } \\
\text { pts }\end{array} \\
64\end{array}$} & \multirow{4}{*}{$\begin{array}{c}\begin{array}{c}\text { PD-L1 } \\
\text { evaluated pts }\end{array} \\
62\end{array}$} & \multirow{4}{*}{$\begin{array}{c}\begin{array}{c}\text { PD-L1 IHC } \\
\text { clone }\end{array} \\
22 C 3\end{array}$} & \multicolumn{2}{|c|}{$\begin{array}{l}\text { PD-L1 } \\
\text { status }\end{array}$} & \multicolumn{2}{|c|}{$\begin{array}{l}\text { ORR according to } \\
\text { PD-L1 status }\end{array}$} & \multicolumn{2}{|c|}{$\begin{array}{l}\text { DCR/clinical benefit } \\
\text { according to PD-L1 } \\
\text { status }\end{array}$} & \multicolumn{2}{|c|}{$\begin{array}{l}\text { mPFS according to PD-L1 status } \\
\text { (months) }\end{array}$} & \multicolumn{3}{|c|}{$\begin{array}{l}\text { mOS according to PD-L1 status } \\
\text { (months) }\end{array}$} \\
\hline & & & & & & & $<1 \%$ & 28 & $7 \%$ & $\mathrm{p}=0.021$ & & NA & 2.8 & $\mathrm{p}=0.034$ & 9.9 & & $p=0.50$ \\
\hline & & & & & & & $1-49 \%$ & & $25 \%$ & & & NA & 4.1 & & 10 & & \\
\hline & & & & & & & $\geqslant 50 \%$ & 14 & $43 \%$ & & & NA & 4.9 & & 12.5 & & \\
\hline Quispel-Janssen & II & $2 n d / 3 r d$ & Nivolumab & 34 & 33 & $28-8$ & $<1 \%$ & 24 & $21 \%$ & NA & $33 \%$ & $\mathrm{p}=0.43$ & NA & NA & NA & & NA \\
\hline$[130]$ & & line & & & & & $\geqslant 1 \%$ & 9 & $44 \%$ & & $55 \%$ & & NA & & NA & & \\
\hline \multirow[t]{2}{*}{ MERIT [127] } & II & $2 n d / 3 r d$ & Nivolumab & 34 & 32 & $28-8$ & $<1 \%$ & 12 & $8 \%$ & NA & NA & NA & $\sim 3$ & HR $0.725(0.316-1.668)$ & $\sim 12$ & & HR $0.542(0.208-1.415)$ \\
\hline & & line & & & & & $\geqslant 1 \%$ & 20 & $40 \%$ & & & & $\sim 8$ & $p=0.4490$ & $\sim 17$ & & $\mathrm{p}=0.2021$ \\
\hline \multirow[t]{2}{*}{ Dutch EAP [136] } & Restrospective & $\geqslant 2 n d$ & Nivolumab & 107 & 33 & SP263 or & $<1 \%$ & 22 & $9 \%$ & OR $1.31(1.00-$ & $36 \%$ & NA & $\sim 3$ & HR $0.52(0.23-1.20)$ & $\sim 6$ & & HR $0.67(0.27-1.64)$ \\
\hline & analysis & line & & & & $22 \mathrm{C} 3$ & $\geqslant 1 \%$ & 11 & $36 \%$ & $\begin{array}{c}1.72) \\
p=0.05\end{array}$ & $54 \%$ & & $\sim 4.5$ & $p=0.12$ & $\sim 6$ & & $p=0.39$ \\
\hline \multirow[t]{4}{*}{$\begin{array}{l}\text { JAVELIN } \\
\text { Solid Tumor [132] }\end{array}$} & Ib & $\begin{array}{l}\geqslant 2 n d \\
\text { line }\end{array}$ & Avelumab & 53 & 43 & $\begin{array}{l}\text { Dako 73- } \\
\quad 10\end{array}$ & $<1 \%$ & 21 & $10 \%$ & $p=1.0$ & $\mathrm{NA}$ & NA & $\begin{array}{c}1.6 \\
(1.4-6.8)\end{array}$ & HR 0.68 (0.34-1.36) & $7.5(3.8-$ & 21.0) & HR $0.56(0.26-1.23)$ \\
\hline & & & & & & & $\geqslant 1 \%$ & 22 & $14 \%$ & & & & $\begin{array}{c}5.3 \\
(1.4-12.0)\end{array}$ & & $20.2(6.1$ & -NE) & \\
\hline & & & & & & & $<5 \%$ & 27 & $7 \%$ & $p=0.34$ & & & $\begin{array}{c}1.7 \\
(1.4-8.3)\end{array}$ & HR 0.64 (0.30-1.34) & $\begin{array}{r}10.2(3 \\
21.0\end{array}$ & & HR 0.62 (0.27-1.42) \\
\hline & & & & & & & $\geqslant 5 \%$ & 16 & $19 \%$ & & & & $\begin{array}{c}5.3 \\
(1.4-17.8)\end{array}$ & & $20.2(4.9$ & -NE) & \\
\hline \multirow[t]{3}{*}{ INITIATE [133] } & II & $\geqslant 2$ nd & Nivolumab & 34 & 34 & $22 \mathrm{C3}$ & $<1 \%$ & 19 & $16 \%$ & $\mathrm{p}=0.018$ & $32 \%$ & $\mathrm{p}=0.037$ & 4 & HR $0.39(0.17-0.94)$ & $\sim 10$ & & HR $0.16(0.04-0.73)$ \\
\hline & & line & +ipilimumab & & & & $\geqslant 1 \%$ & 15 & $47 \%$ & & $73 \%$ & & $\sim 11$ & & NR & & \\
\hline & & & & & & & $\geqslant 50 \%$ & 5 & NA & & $80 \%$ & & NA & & NA & & \\
\hline \multirow{4}{*}{$\begin{array}{l}\text { IFCT-1501 MAPS2 } \\
{[134,135]}\end{array}$} & II & $\geqslant 2$ nd & Nivolumab & 125 & $99^{\#}$ & $28-8 /$ & $<1 \%$ & 581 & $12.1 \%$ & $\mathrm{p}=0.002$ & $41.4 \%$ & $\mathrm{p}=0.23$ & NA & NA & NA & & NA \\
\hline & & line & & & & SP-263 & $\geqslant 1 \%$ & 41 & $39 \%$ & & $57.3 \%$ & & & & & & \\
\hline & & & Nivolumab & & & & $<25 \%$ & 921 & $16.6 \%$ & $\mathrm{p}=0.007$ & $43.5 \%$ & $p=0.047$ & & & & & \\
\hline & & & +ipilimumab & & & & $\geqslant 25 \%$ & 77 & $71.4 \%$ & & $85.7 \%$ & & & & & & \\
\hline \multirow[t]{6}{*}{ NIBIT-MESO-1 [129] } & II & $\begin{array}{l}\text { 1st/2nd } \\
\text { line }\end{array}$ & $\begin{aligned} & \text { Durvalumab } \\
& \text { +tremelimumab }\end{aligned}$ & 40 & 38 & SP263 & $<1 \%$ & 18 & $22 \%$ & $\begin{array}{c}\text { nonsignificant } \\
\text { p-values }\end{array}$ & $50 \% n$ & $\begin{array}{l}\text { onsignificant } \\
\text { p-values }\end{array}$ & $\begin{array}{c}5.2 \\
(4.5-5.8)\end{array}$ & $\begin{array}{c}\text { nonsignificant } \\
\text { p-values }\end{array}$ & $\begin{array}{l}\text { 1-year } \\
\text { os rate }\end{array}$ & $42 \%$ & $\begin{array}{c}\text { nonsignificant } \\
\text { p-values }\end{array}$ \\
\hline & & & & & & & $\geqslant 1 \%$ & 20 & $35 \%$ & & $75 \%$ & & $\begin{array}{c}11.7 \\
(6.9-16.5)\end{array}$ & & & $66 \%$ & \\
\hline & & & & & & & $\geqslant 5 \%$ & 17 & $35 \%$ & & $71 \%$ & & $\begin{array}{c}8.5 \\
(7.7-9.1)\end{array}$ & & & $59 \%$ & \\
\hline & & & & & & & $\geqslant 10 \%$ & 11 & $27 \%$ & & $73 \%$ & & $\begin{array}{c}8.5 \\
(7.5-9.4)\end{array}$ & & & $55 \%$ & \\
\hline & & & & & & & $\geqslant 25 \%$ & 7 & $43 \%$ & & $86 \%$ & & $\begin{array}{c}8.5 \\
(8.2-8.7)\end{array}$ & & & $62 \%$ & \\
\hline & & & & & & & $\geqslant 50 \%$ & 4 & $25 \%$ & & $75 \%$ & & $\begin{array}{c}11.7(8.9- \\
14.5)\end{array}$ & & & $66 \%$ & \\
\hline
\end{tabular}




\begin{tabular}{|c|c|c|c|c|c|c|c|c|c|c|c|c|c|c|c|c|}
\hline \multirow{2}{*}{$\begin{array}{l}\text { Study } \\
\text { PROMISE-meso [104] }\end{array}$} & \multirow{2}{*}{$\begin{array}{l}\text { Phase } \\
\text { III }\end{array}$} & \multirow{2}{*}{$\begin{array}{l}\text { Setting } \\
\text { 2nd line }\end{array}$} & \multirow{2}{*}{$\begin{array}{c}\text { Treatment } \\
\text { Pembrolizumab }\end{array}$} & \multirow{2}{*}{$\begin{array}{c}\begin{array}{c}\text { Total } \\
\text { pts }\end{array} \\
73\end{array}$} & \multirow{2}{*}{$\begin{array}{c}\begin{array}{c}\text { PD-L1 } \\
\text { evaluated pts }\end{array} \\
67\end{array}$} & \multirow{2}{*}{$\begin{array}{l}\begin{array}{c}\text { PD-L1 IHC } \\
\text { clone }\end{array} \\
\text { SP263 }\end{array}$} & \multicolumn{2}{|c|}{$\begin{array}{l}\text { PD-L1 } \\
\text { status }\end{array}$} & \multicolumn{2}{|c|}{$\begin{array}{l}\text { ORR according to } \\
\text { PD-L1 status }\end{array}$} & \multicolumn{2}{|c|}{$\begin{array}{l}\text { DCR/clinical benefit } \\
\text { according to PD-L1 } \\
\text { status }\end{array}$} & \multicolumn{2}{|c|}{$\begin{array}{l}\text { mPFS according to PD-L1 status } \\
\text { (months) }\end{array}$} & \multicolumn{2}{|c|}{$\begin{array}{l}\text { mOS according to PD-L1 status } \\
\text { (months) }\end{array}$} \\
\hline & & & & & & & $<1 \%$ & 36 & NA & NA & NA & NA & $\begin{array}{c}3.7 \\
(2.1-4.2)\end{array}$ & $\begin{array}{l}\text { See the text for } \\
\text { HR between }\end{array}$ & $9.2(6.0-19.2)$ & $\begin{array}{l}\text { See the text for } \\
\text { HR between }\end{array}$ \\
\hline & & & & & & & $\geqslant 1 \%$ & 31 & & & & & $\begin{array}{c}4.1 \\
(1.9-4.3)\end{array}$ & treatment arms & 13.8 (7.5-NE) & treatment arms \\
\hline & & & $\begin{array}{l}\text { Gemcitabline/ } \\
\text { vinorelbine }\end{array}$ & 71 & 62 & & $<1 \%$ & 30 & & & & & $\begin{array}{c}3.4 \\
(2.0-4.3)\end{array}$ & & $9.5(5.6-13.8)$ & \\
\hline & & & & & & & $\geqslant 1 \%$ & 32 & & & & & $\begin{array}{c}2.5 \\
(2.1-6.4)\end{array}$ & & 15.3 (6.4-NE) & \\
\hline DREAM [105] & "I & 1st line & $\begin{array}{l}\text { Durvalumab+Cisplatin } \\
\quad+\text { Pemetrexed }\end{array}$ & 54 & 51 & SP263 & $<1 \%$ & 24 & NA & NA & NA & NA & $\begin{array}{c}6.3 \\
(5.3-10.4)\end{array}$ & $\begin{array}{l}\text { Non apparent } \\
\text { differences }\end{array}$ & NA & NA \\
\hline & & & & & & & $\geqslant 1 \%$ & 27 & & & & & $\begin{array}{c}6.6 \\
(5.5-9.0)\end{array}$ & & & \\
\hline PrE0505 [106] & ॥ & 1st line & Durvalumab+Cisplatin & 55 & 41 & E1L3N & $<1 \%$ & 19 & NA & NA & NA & NA & NA & NA & 19.6 & $p=0.97$ \\
\hline & & & +Pemetrexed & & & & $1-49 \%$ & 10 & & & & & & & 20.8 & \\
\hline & & & & & & & $\geqslant 50 \%$ & 12 & & & & & & & 18.7 & \\
\hline \multirow[t]{4}{*}{ CheckMate $743[7]$} & III & 1st line & $\begin{array}{l}\text { Nivolumab } \\
\text { +ipilimumab }\end{array}$ & 303 & 289 & $28-8$ & $<1 \%$ & 58 & NA & NA & NA & NA & NA & NA & $\begin{array}{c}17.3 \\
(10.1-24.3)\end{array}$ & $\begin{array}{l}\text { See the text for } \\
\text { HR between }\end{array}$ \\
\hline & & & & & & & $\geqslant 1 \%$ & 231 & & & & & & & $18(16.8-21.5)$ & treatment arms \\
\hline & & & $\begin{array}{l}\text { Platinum salt } \\
\text { +pemetrexed }\end{array}$ & 302 & 297 & & $<1 \%$ & 77 & & & & & & & $\begin{array}{c}16.5 \\
(13.4-20.5)\end{array}$ & \\
\hline & & & & & & & $\geqslant 1 \%$ & 220 & & & & & & & $\begin{array}{c}13.3 \\
(11.6-15.4)\end{array}$ & \\
\hline
\end{tabular}

Pts: Patients; IHC: Immunohistochemistry; ORR: Objective response rate; DCR: Disease-control rate; mPFS: Median progression-free survival; mOS: Median overall survival; NA: Not available; HR: Hazard ratio; NE: Not estimable; NR: Not reached. ": Results are reported with regard to PD-L1 evaluation with 28.8 clone. Data between parenthesis indicate $95 \%$ confidence intervals. 


\begin{tabular}{|c|c|c|c|c|c|c|c|}
\hline $\begin{array}{l}\text { First author } \\
\text { [ref.] }\end{array}$ & Phase & Treatment & $\mathrm{n}$ & $\begin{array}{l}\text { RR/ DCR } \\
\text { (\%) }\end{array}$ & $\begin{array}{c}\text { PFS } \\
\text { months }\end{array}$ & OS months & $\begin{array}{c}\text { irAEs grade } \\
\geqslant 3(\%)\end{array}$ \\
\hline Giaccone [142] & II & Pembrolizumab & $\begin{array}{l}40 \\
\mathrm{TC}\end{array}$ & $23 / 76$ & 4.2 & $\begin{array}{l}\text { 24.9. (4-year OS: } \\
30 \%)\end{array}$ & 15 \\
\hline Сно [143] & II & Pembrolizumab & $\begin{array}{l}26 \\
\mathrm{TC}\end{array}$ & $19 / 73$ & 6.1 & 14.5 & 15.4 \\
\hline & & & $7 \mathrm{~T}$ & $29 / 100$ & & NR & 71.4 \\
\hline KATSUYA [145] & II & Nivolumab & $\begin{array}{l}13 \\
\mathrm{TC}\end{array}$ & $0 / 38$ & 3.8 & Nt R & 15 \\
\hline HeERY [144] & 1 & Avelumab & $\begin{array}{c}7 \mathrm{~T} \\
1 \mathrm{TC}\end{array}$ & 5 & $50 /$ Nt R & Nt R & 68 \\
\hline
\end{tabular}

advanced disease with no standard second-line treatment [137]. In TET, PD-L1 expression has been reported from $36 \%$ to $75 \%$ of TC [138-140], however, the prognosis and predictive value of PD-L1 expression remains controversial. In TC, the staining pattern showed high PD-L1 concordance among four assays with different antibodies (SP142, SP263, 22C3, and 28-8) [141]. This evidence prompted evaluation of the role of immunotherapy in TET, mainly in TC, as autoimmune disorders are uncommon in TC patents (table 7) [142-145]. In this subset of thoracic malignancies, ICI reported a RR of 20\%, median PFS of 4 months, with a correlation between PD-L1 expression and efficacy [142, 143].

\section{Conclusions}

The immune background of thoracic malignancies is the basis for the therapeutic success of ICIs therapies. These latter have become the standard of care in NSCLC and SCLC, while their role in MPM and TET will hopefully be defined. The magnitude of clinical benefit observed in NSCLC since the introduction of ICI strategy is thus far unparalleled, as they have become the new standard backbone for the first-line treatment of advanced disease, and have showed their impact in earlier stages. In other thoracic tumours, evidence thus far available sustains the role of ICIs therapies in a subset of patients.

PD-L1 and to a lower extent TMB are useful, albeit non-perfect, biomarkers to address treatment options in NSCLC, while no biological-clinical element can suggest thus far who are the patients more suitable to derive benefit from ICI administration in SCLC and TET. In MPM, very recent evidence will likely change the standard of care in the setting of non-epithelioid malignancies, as double PD-1/CTLA-4 blockade performs far better than chemotherapy.

The better understanding of the immune context of thoracic tumours is expected to shed light on additional biomarkers to be adopted in the clinical practice, as well to help the recognition of novel therapeutic targets and strategies.

Provenance: Commissioned article, peer reviewed.

Previous articles in this series: No. 1: Eichhorn F, Winter H. How to handle oligometastatic disease in nonsmall cell lung cancer. Eur Respir Rev 30: 2021; 200234. No. 2: Asciak R, George V, Rahman NM. Update on biology and management of mesothelioma. Eur Respir Rev 30: 2021; 200226. No. 3: Finazzi T, Schneiders FL, Senan S. Developments in radiation techniques for thoracic malignancies. Eur Respir Rev 30: 2021; 200224. No. 4: Huber RM, Kauffmann-Guerrero D, Hoffmann $\mathrm{H}$, et al. New developments in locally advanced nonsmall cell lung cancer. Eur Respir Rev 30: 2021; 200227. No. 5: Rittmeyer A, Schiwitza A, Sahovic L, et al. Update on recent key publications in lung oncology: picking up speed. Eur Respir Rev 30: 2021; 200300. No. 6: Abdayem P, Planchard D. Update on molecular pathology and role of liquid biopsy in nonsmall cell lung cancer. Eur Respir Rev 30: 2021; 200294. No. 7: Lam S, Tammemagi M. Contemporary issues in the implementation of lung cancer screening. Eur Respir Rev 30: 2021; 200288. No. 8: Ghigna M-R, Thomas de Montpreville V. Mediastinal tumours and pseudo-tumours: a comprehensive review with emphasis on multidisciplinary approach. Eur Respir Rev 30: 2021; 200309. 
Conflict of interest: J. Remon reports other funding support from MSD, Boehringer Ingelheim, Pfizer, BMS, AstraZeneca and Roche, and personal fees and other funding support from OSE Immunotherapeutics, outside the submitted work. F. Facchinetti has nothing to disclose. B. Besse reports grants from Abbvie, Amgen, AstraZeneca, Biogen, Blueprint Medicines, BMS, Celgène, Eli-Lilly, GSK, Ignyta, IPSEN, Merck KGaA, MSD, Nektar, Onxeo, Pfizer, Pharma Mar, Sanofi, Spectrum Pharmaceuticals, Takeda, and Tiziana Pharma, outside the submitted work.

\section{References}

1 Gettinger S, Horn L, Jackman D, et al. Five-year follow-up of nivolumab in previously treated advanced non-small-cell lung cancer: Results from the CA209-003 study. J Clin Oncol 2018; 36: 1675-1684.

2 Garon EB, Hellmann MD, Rizvi NA, et al. Five-year overall survival for patients with advanced non-small-cell lung cancer treated with pembrolizumab: Results from the phase I KEYNOTE-001 study. J Clin Oncol 2019; 37: 2518-2527.

3 Herbst RS, Garon EB, Kim D-W, et al. Long-term outcomes and retreatment among patients with previously treated, programmed death-ligand 1-Positive, Advanced Non-Small-Cell Lung Cancer in the KEYNOTE-010 Study. J Clin Oncol 2020; 38: 1580-1590.

4 Horn L, Mansfield AS, Szczęsna A, et al. First-Line atezolizumab plus chemotherapy in extensive-stage small-cell lung cancer. N Engl J Med 2018; 379: 2220-2229.

5 Paz-Ares L, Dvorkin M, Chen $\mathrm{Y}$, et al. Durvalumab plus platinum-etoposide versus platinum-etoposide in first-line treatment of extensive-stage small-cell lung cancer (CASPIAN): a randomised, controlled, open-label, phase 3 trial. Lancet 2019; 394: 1929-1939.

6 Paz-Ares LG, Dvorkin M, Chen $\mathrm{Y}$, et al. Durvalumabttremelimumab+platinum-etoposide in first-line extensive-stage SCLC (ES-SCLC): Updated results from the phase III CASPIAN study. J Clin Oncol 2020; 38; Suppl. 15, 9002-9002.

7 Baas P, Scherpereel A, Nowak AK, et al. First-line nivolumab plus ipilimumab in unresectable malignant pleural mesothelioma (CheckMate 743): a multicentre, randomised, open-label, phase 3 trial. Lancet 2021; 397: 375-386.

8 Remon J, Passiglia F, Ahn M-J, et al. Immune checkpoint inhibitors in thoracic malignancies: review of the existing evidence by an IASLC expert panel and recommendations. J Thorac Oncol 2020; 15: 914-947.

9 Antonia SJ, Borghaei H, Ramalingam SS, et al. Four-year survival with nivolumab in patients with previously treated advanced non-small-cell lung cancer: a pooled analysis. Lancet Oncol 2019; 20: 1395-1408.

10 Gettinger S, Borghaei H, Brahmer J, et al. Five-Year Outcomes From the Randomized, Phase 3 Trials CheckMate 017/057: Nivolumab versus Docetaxel in Previously Treated NSCLC. J Thoracic Oncol 2019; 14: S244-S245.

11 Aguilar EJ, Ricciuti B, Gainor JF, et al. Outcomes to first-line pembrolizumab in patients with non-small-cell lung cancer and very high PD-L1 expression. Ann Oncol 2019; 30: 1653-1659.

12 Tsao MS, Kerr KM, Kockx M, et al. PD-L1 immunohistochemistry comparability study in real-life clinical samples: results of blueprint phase 2 project. J Thorac Oncol 2018; 13: 1302-1311.

13 Herbst RS, Soria JC, Kowanetz M, et al. Predictive correlates of response to the anti-PD-L1 antibody MPDL3280A in cancer patients. Nature 2014; 515: 563-567.

14 Hong L, Negrao MV, Dibaj SS, et al. Programmed death-ligand 1 heterogeneity and its impact on benefit from immune checkpoint inhibitors in NSCLC. J Thorac Oncol 2020; 15: 1449-1459.

15 Reck M, Rodríguez-Abreu D, Robinson AG, et al. Pembrolizumab versus chemotherapy for PD-L1-positive non-small-cell lung cancer. N Engl J Med 2016; 375: 1823-1833.

16 Mok TSK, Wu Y-L, Kudaba I, et al. Final analysis of the phase III KEYNOTE-042 study: Pembrolizumab (Pembro) versus platinum-based chemotherapy (Chemo) as first-line therapy for patients (Pts) with PD-L1positive locally advanced/metastatic NSCLC. Ann Oncol 2019; 30: i38.

17 Herbst RS, Giaccone G, de Marinis F, et al. Atezolizumab for first-line treatment of PD-L1-selected patients with NSCLC. N Engl J Med 2020; 383: 1328-1339.

18 Sezer A, Kilickap S, Gümüş M, et al. EMPOWER-Lung 1: Phase III first-line (1 L) cemiplimab monotherapy versus platinum-doublet chemotherapy (chemo) in advanced non-small cell lung cancer (NSCLC) with programmed cell death-ligand 1 (PD-L1) $\geqslant 50 \%$. Ann Oncol 2020; 31: S1182-S1183.

19 Ramalingam SS, Ciuleanu TE, Pluzanski A, et al. Nivolumab+ipilimumab versus platinum-doublet chemotherapy as first-line treatment for advanced non-small cell lung cancer: Three-year update from CheckMate 227 Part 1. J Clin Oncol 2020; 38; Suppl. 15, 9500-9500.

20 Hellmann MD, Paz-Ares L, Bernabe Caro R, et al. Nivolumab plus Ipilimumab in advanced non-small-cell lung cancer. N Engl J Med 2019; 381: 2020-2031.

21 Rodriguez-Abreu D, Powell SF, Hochmair M, et al. Final analysis of KEYNOTE-189: Pemetrexed-platinum chemotherapy (chemo) with or without pembrolizumab (pembro) in patients (pts) with previously untreated metastatic nonsquamous non-small cell lung cancer (NSCLC). J Clin Oncol 2020; 38; Suppl. 15, 9582-9582. 
West $\mathrm{H}$, McCleod M, Hussein M, et al. Atezolizumab in combination with carboplatin plus nab-paclitaxel chemotherapy compared with chemotherapy alone as first-line treatment for metastatic non-squamous non-small-cell lung cancer (IMpower130): a multicentre, randomised, open-label, phase 3 tria. Lancet Oncol 2019; 20: 924-937.

Socinski MA, Jotte RM, Cappuzzo F, et al. Atezolizumab for first-line treatment of metastatic nonsquamous NSCLC. N Eng J Med 2018; 378: 2288-2301.

Socinski MA, Jotte RM, Cappuzzo F, et al. Overall survival (OS) analysis of IMpower150, a randomised Ph 3 study of atezolizumab (atezo)+chemotherapy (chemo) \pm bevacizumab (bev) versus chemo+bev in $1 \mathrm{~L}$ nonsquamous (NSQ) NSCLC. J Clin Oncol 2018; 36; Suppl. 15, 9002-9002.

Yang Y, Wang Z, Fang J, et al. Efficacy and safety of sintilimab plus pemetrexed and platinum as first-line treatment for locally advanced or metastatic nonsquamous non-small cell lung cancer: a randomised, double-blind, phase 3 study (ORIENT-11). J Thoracic Oncol 2020; 15: 1636-1646.

Paz-Ares L, Vicente D, Tafreshi A, et al. A randomised, placebo-controlled trial of pembrolizumab plus chemotherapy in patients with metastatic squamous non-small-cell lung cancer: protocol-specified final analysis of KEYNOTE-407. J Thoracic Oncol 2020; 15: 1657-1667.

Zhou C, Wu L, Fan Y, et al. ORIENT-12: Sintilimab plus gemcitabine and platinum (GP) as first-line (1 L) treatment for locally advanced or metastatic squamous non-small-cell lung cancer (sqNSCLC). Ann Oncol 2020; 31: S1186.

Reck M, Ciuleanu T-E, Dols MC, et al. Nivolumab (NIVO)+ipilimumab (IPI)+2 cycles of platinum-doublet chemotherapy (chemo) versus 4 cycles chemo as first-line $(1 \mathrm{~L})$ treatment (tx) for stage IV/recurrent non-small cell lung cancer (NSCLC): CheckMate 9LA. J Clin Oncol 2020; 38; Suppl. 15, 9501-9501.

Carbone DP, Reck M, Paz-Ares L, et al. First-line nivolumab in stage IV or recurrent non-small-cell lung cancer. N Engl J Med 2017; 376: 2415-2426.

Barlesi F, Nishio M, Cobo M, et al. IMpower132: efficacy of atezolizumab (atezo)+carboplatin (carbo)/cisplatin (cis)+pemetrexed (pem) as $1 \mathrm{~L}$ treatment in key subgroups with stage IV non-squamous non-small cell lung cancer (NSCLC). Ann Oncol 2018; 29: 959-965.

Jotte R, Cappuzzo F, Vynnychenko I, et al. Atezolizumab in combination with carboplatin and Nab-Paclitaxel in advanced squamous NSCLC (IMpower131): results from a randomised phase III trial. $J$ Thoracic Oncol 2020; 15: 1351-1360.

Rizvi NA, Cho BC, Reinmuth N, et al. Durvalumab with or without tremelimumab versus standard chemotherapy in first-line treatment of metastatic non-small cell lung cancer: the MYSTIC phase 3 randomised clinical trial. JAMA Oncol 2020; 6: 661-674.

Brahmer JR, Rodriguez-Abreu D, Robinson AG, et al. KEYNOTE-024 5-year OS update: First-line (1 L) pembrolizumab (pembro) versus platinum-based chemotherapy (chemo) in patients (pts) with metastatic NSCLC and PD-L1 tumour proportion score (TPS) $\geqslant 50 \%$. Ann Oncol 2020; 31: S1181-S1182.

Spigel D, de Marinis F, Giaccone G, et al. IMpower110: Interim overall survival (OS) analysis of a phase III study of atezolizumab (atezo) versus platinum-based chemotherapy (chemo) as first-line $(1 \mathrm{~L})$ treatment (tx) in PD-L1-selected NSCLC. Ann Oncol 2019; 30: Suppl. 5, v915.

Reck M, Rodríguez-Abreu D, Robinson AG, et al. KEYNOTE-024 3-Year survival update: Pembrolizumab versus platinum-based chemotherapy for advanced non-small-cell lung cancer. J Thoracic Oncol 2019; 14: S243.

Mok TSK, Wu Y-L, Kudaba I, et al. Pembrolizumab versus chemotherapy for previously untreated, PD-L1expressing, locally advanced or metastatic non-small-cell lung cancer (KEYNOTE-042): a randomised, open-label, controlled, phase 3 trial. Lancet 2019; 393: 1819-1830.

Ferrara R, Facchinetti F, Calareso G, et al. Hyperprogressive disease (HPD) upon first-line PD-1/PD-L1 inhibitors $(\mathrm{ICl})$ as single agent or in combination with platinum-based chemotherapy in non-small cell lung cancer (NSCLC) patients (pts). Ann Oncol 2020; 31: S826.

Garassino MC, Gadgeel S, Esteban E, et al. Outcomes among patients (pts) with metastatic nonsquamous NSCLC with liver metastases or brain metastases treated with pembrolizumab (pembro) plus pemetrexed-platinum: Results from the KEYNOTE-189 study. Cancer Res 2019; 79; Suppl. 13, СT043.

Paz-Ares L, Ciuleanu TE, Yu X, et al. Nivolumab (NIVO)+platinum-doublet chemotherapy (chemo) versus chemo as first-line $(1 \mathrm{~L})$ treatment (tx) for advanced non-small cell lung cancer (aNSCLC): CheckMate 227 part 2 final analysis. Ann Oncol 2019; 30: xi67-xi68.

Leighl NB, Laurie SA, Goss GD, et al. CCTG BR.34: a randomised trial of durvalumab and tremelimumab \pm platinum-based chemotherapy in patients with metastatic (Stage IV) squamous or nonsquamous non-small cell lung cancer (NSCLC). J Clin Oncol 2020; 38: 9502.

4 Rodriguez-Abreu D, Powell SF, Hochmair M, et al. Final analysis of KEYNOTE-189: Pemetrexed-platinum chemotherapy (chemo) with or without pembrolizumab (pembro) in patients (pts) with previously untreated metastatic nonsquamous non-small cell lung cancer (NSCLC). J Clin Oncol 2020; 38; Suppl 15. 9582-9582.

Popat V, Lu R, Ahmed M, et al. Lack of association between radiographic tumor burden and efficacy of immune checkpoint inhibitors in advanced lung cancer. Oncologist 2020; 25: 515-522. 
Faehling M, Kopp M, Schwenk B, et al. Immuno-oncological treatment and tumor mass in non-small cell lung cancer: case-control analysis of overall survival in routine clinical practice. Oncology 2019; 97: 228-235.

Seban R-D, Mezquita L, Berenbaum A, et al. Baseline metabolic tumor burden on FDG PET/CT scans predicts outcome in advanced NSCLC patients treated with immune checkpoint inhibitors. Eur J Nucl Med Mol Imaging 2020; 47: 1147-1157.

Hopkins AM, Kichenadasse G, McKinnon RA, et al. Baseline tumor size and survival outcomes in lung cancer patients treated with immune checkpoint inhibitors. Semin Oncol 2019; 46: 380-384.

Addeo A, Banna GL, Metro G, et al. Chemotherapy in combination with immune checkpoint inhibitors for the first-line treatment of patients with advanced non-small cell lung cancer: a systematic review and literature-based meta-analysis. Front Oncol 2019; 9: 264.

Borghaei H, Langer C, Paz-Ares L, et al. Pembrolizumab plus chemotherapy for advanced NSCLC without Tumor PD-L1 expression: pooled analysis of KN021G, KN189 and KN407. J Thoracic Oncol 2019; 14: S1124.

Teixido C, Reguart N. Using biomarkers to determine optimal combinations with immunotherapy (biomarker discovery perspective). Future Oncol 2020; 16: 1677-1681.

Shim JH, Kim HS, Cha H, et al. HLA-corrected tumor mutation burden and homologous recombination deficiency for the prediction of response to PD-(L)1 blockade in advanced non-small-cell lung cancer patients. Ann Oncol 2020; 31: 902-911.

Rizvi NA, Hellmann MD, Snyder A, et al. Mutational landscape determines sensitivity to PD-1 blockade in non-small cell lung cancer. Science 2015; 348: 124-128.

Ready N, Hellmann MD, Awad MM, et al. First-line Nivolumab plus Ipilimumab in advanced non-small-cell lung cancer (CheckMate 568): outcomes by programmed death ligand 1 and tumor mutational burden as biomarkers. J Clin Oncol 2019; 37: 992-1000.

Hellmann MD, Ciuleanu T-E, Pluzanski A, et al. nivolumab plus ipilimumab in lung cancer with a high tumor mutational burden. N Engl J Med 2018; 378: 2093-2104.

Herbst RS, Lopes G, Kowalski DM, et al. Association between tissue TMB (tTMB) and clinical outcomes with pembrolizumab monotherapy (pembro) in PD-L1-positive advanced NSCLC in the KEYNOTE-010 and -042 trials. Ann Oncol 2019; 30: v916-v917.

Garassino M, Rodriguez-Abreu D, Gadgeel S, et al. Evaluation of TMB in KEYNOTE-189: pembrolizumab plus chemotherapy versus placebo plus chemotherapy for nonsquamous NSCLC. J Thoracic Oncol 2019; 14: S216-S217.

Marabelle A, Fakih MG, Lopez J, et al. Association of tumour mutational burden with outcomes in patients with select advanced solid tumours treated with pembrolizumab in KEYNOTE-158. Ann Oncol 2019; 30: v477-v478.

Fabrizio D, Lieber D, Malboeuf C, et al. A blood-based next-generation sequencing assay to determine tumor mutational burden (bTMB) is associated with benefit to an anti-PD-L1 inhibitor, atezolizumab. Cancer Res 2018; 78: Suppl. 13, 5706-5717.

Socinski M, Velcheti V, Mekhail T, et al. Final efficacy results from B-F1RST, a prospective phase II trial evaluating blood-based tumour mutational burden (bTMB) as a predictive biomarker for atezolizumab (atezo) in $1 \mathrm{~L}$ non-small cell lung cancer (NSCLC). Ann Oncol 2019; 30: Suppl. 5, V919-V920.

AstraZeneca. Update on the Phase III NEPTUNE trial of Imfinzi plus tremelimumab in Stage IV non-small cell lung cancer. www.astrazeneca.com/media-centre/press-releases/2019/update-on-the-phase-iii-neptune-trialof-imfinzi-plus-tremelimumab-in-stage-iv-non-small-cell-lung-cancer-21082019.html Date last updated: 21 August 2019.

Hopkins AM, Kichenadasse G, McKinnon RA, et al. Baseline tumor size and survival outcomes in lung cancer patients treated with immune checkpoint inhibitors. Semin Oncol 2019; 46: 380-384.

Skoulidis F, Goldberg ME, Greenawalt DM, et al. STK11/LKB1 mutations and PD-1 inhibitor resistance in KRAS-mutant lung adenocarcinoma. Cancer Discov 2018; 8: 822-835.

1 Herbst RS, Lopes G, Kowalski DM, et al. LBA4 Association of KRAS mutational status with response to pembrolizumab monotherapy given as first-line therapy for PD-L1-positive advanced non-squamous NSCLC in KEYNOTE-042. Ann Oncol 2019; 30: 63-64.

2 Gadgeel S, Rodriguez-Abreu D, Felip E, et al. KRAS mutational status and efficacy in KEYNOTE-189: Pembrolizumab (pembro) plus chemotherapy (chemo) versus placebo plus chemo as first-line therapy for metastatic non-squamous NSCLC. Ann Oncol 2019; 30: 839-844.

3 Skoulidis F, Arbour KC, Hellmann MD, et al. Association of STK11/LKB1 genomic alterations with lack of benefit from the addition of pembrolizumab to platinum doublet chemotherapy in non-squamous non-small cell lung cancer. J Clin Oncol 2019; 37; Suppl 15., 102-102.

64 Cho BJ, Lopes G, Kowalski DM, et al. Relationship between STK11 and KEAP1 mutational status and efficacy in KEYNOTE 04: pembrolizumab monotherapy versus platinum-based chemotherapy as first-line therapy for PD-L1 positive advanced NSCLC. 2020 American Association for Cancer Research virtual Annual Meeting; April 27-28, 2020 Abstract CT084. 
West H, Cappuzzo F, Reck M, et al. IMpower150: a post hoc analysis of efficacy outcomes in patients with KRAS, STK11 and KEAP1 mutations. Ann Oncol 2020; 31: S817-S818.

Rizvi N, Cho BC, Reinmuth N, et al. Mutations associated with sensitivity or resistance to immunotherapy in mNSCLC: analysis from the MYSTIC trial. J Thoracic Oncol 2019; 14: S217.

Reck M, Bondarenko I, Luft A, et al. Ipilimumab in combination with paclitaxel and carboplatin as first-line therapy in extensive-disease-small-cell lung cancer: results from a randomised, double-blind, multicenter phase 2 trial. Ann Oncol 2013; 24: 75-83.

Pelosof LC, Gerber DE. Paraneoplastic syndromes: An approach to diagnosis and treatment. Mayo Clin Proc 2010: 85: 838-854.

Graus F, Dalmau J, Reñé R, et al. Anti-Hu antibodies in patients with small-cell lung cancer: association with complete response to therapy and improved survival. J Clin Oncol 1997; 15: 2866-2872.

Muppa P, Parrilha Terra SBS, Sharma A, et al. Immune cell infiltration may be a key determinant of long-term survival in small cell lung cancer. J Thorac Oncol 2019; 14: 1286-1295.

Wang H, Li Z, Dong B, et al. Prognostic significance of PD-L1 expression and CD8+ T cell infiltration in pulmonary neuroendocrine tumors. Diagn Pathology 2018; 13: 30.

Guleria P, Kumar S, Malik PS, et al. PD-L1 expression in small cell and large cell neuroendocrine carcinomas of lung: an immunohistochemical study with review of literature. Pathol Oncol Res 2020; 26: 2363-2370.

Kim HS, Lee JH, Nam SJ, et al. Association of PD-L1 expression with tumor-infiltrating immune cells and mutation burden in high-grade neuroendocrine carcinoma of the lung. $J$ Thorac Oncol 2018; 13: 636-648.

Tsuruoka K, Horinouchi H, Goto Y, et al. PD-L1 expression in neuroendocrine tumors of the lung. Lung Cancer 2017; 108: 115-120.

George J, Walter V, Peifer M, et al. Integrative genomic profiling of large-cell neuroendocrine carcinomas reveals distinct subtypes of high-grade neuroendocrine lung tumors. Nat Commun 2018; 9: 1048.

Ishii $\mathrm{H}$, Azuma K, Kawahara A, et al. Significance of programmed cell death-ligand 1 expression and its association with survival in patients with small cell lung cancer. J Thorac Oncol 2015; 10: 426-430.

Bonanno L, Pavan A, Dieci MV, et al. The role of immune microenvironment in small-cell lung cancer: Distribution of PD-L1 expression and prognostic role of FOXP3-positive tumour infiltrating lymphocytes. Eur J Cancer 2018; 101: 191-200.

Carvajal-Hausdorf D, Altan M, Velcheti V, et al. Expression and clinical significance of PD-L1, B7-H3, B7-H4 and TILs in human small cell lung Cancer (SCLC). J Immunother Cancer 2019; 7: 65.

Yu H, Batenchuk C, Badzio A, et al. PD-L1 expression by two complementary diagnostic assays and mRNA in situ hybridisation in small cell lung cancer. J Thoracic Oncol 2017; 12: 110-120.

Alexandrov LB, Nik-Zainal S, Wedge DC, et al. Signatures of mutational processes in human cancer. Nature 2013; 500: 415-421.

George J, Lim JS, Jang SJ, et al. Comprehensive genomic profiles of small cell lung cancer. Nature 2015; 524: 47-53.

Rudin CM, Awad MM, Navarro A, et al. Pembrolizumab or placebo plus etoposide and platinum as first-line therapy for extensive-stage small-cell lung cancer: randomised, double-blind, Phase III KEYNOTE-604 Study. J Clin Oncol 2020; 38: 2369-2379.

3 Liu SV, Reck M, Mansfield AS, et al. Updated pverall survival and PD-L1 subgroup analysis of patients with extensive-stage small-cell lung cancer treated with atezolizumab, carboplatin, and etoposide (IMpower133) I. J Clin Oncol 2021; 39: 619-630.

84 Leal T, Wang Y, Dowlati A, et al. Randomised phase II clinical trial of cisplatin/carboplatin and etoposide (CE) alone or in combination with nivolumab as frontline therapy for extensive-stage small cell lung cancer (ES-SCLC): ECOG-ACRIN EA5161. J Oncol 2020; 38; Suppl 15., 9000-9000.

5 Owonikoko TK, Kim HR, Govindan R, et al. Nivolumab (nivo) plus ipilimumab (ipi), nivo, or placebo (pbo) as maintenance therapy in patients (pts) with extensive disease small cell lung cancer (ED-SCLC) after first-line $(1 \mathrm{~L})$ platinum-based chemotherapy (chemo): Results from the double-blind, randomised phase III CheckMate 451 study. Ann Oncol 2019; 30: ii77.

Gadgeel SM, Pennell NA, Fidler MJ, et al. Phase II study of maintenance pembrolizumab in patients with extensive-stage small cell lung cancer (SCLC). J Thoracic Oncol 2018; 13: 1393-1399.

87 Reck M, Vicente D, Ciuleanu $T$, et al. Efficacy and safety of nivolumab (nivo) monotherapy versus chemotherapy (chemo) in recurrent small cell lung cancer (SCLC): Results from CheckMate 331. Ann Oncol 2018; 29: $x 43$.

8 Pujol JL, Greillier L, Audigier-Valette C, et al. A randomised non-comparative phase II study of anti-programmed cell death-ligand 1 atezolizumab or chemotherapy as second-line therapy in patients with small cell lung cancer: results from the IFCT-1603 trial. J Thorac Oncol 2019; 14: 903-913.

Chiang AC, Sequist LVD, Gilbert J, et al. Clinical activity and safety of atezolizumab in a phase 1 study of patients with relapsed/refractory small-cell lung cancer. Clin Lung Cancer 2020; 21: 455-463.e4.

Chung HC, Lopez-Martin JA, Kao SC-H, et al. Phase 2 study of pembrolizumab in advanced small-cell lung cancer (SCLC): KEYNOTE-158. J Clin Oncol 2018; 15: 618-627. 
Ott PA, Elez E, Hiret S, et al. Pembrolizumab in patients with extensive-stage small-cell lung cancer: results from the phase Ib KEYNOTE-028 Study. J Clin Oncol 2017; 35: 3823-3829.

Hellmann MD, Callahan MK, Awad MM, et al. Tumor mutational burden and efficacy of nivolumab monotherapy and in combination with Ipilimumab in small-cell lung cancer. Cancer Cell 2018; 33: 853-861.

Ready NE, Ott PA, Hellmann MD, et al. Nivolumab monotherapy and nivolumab plus ipilimumab in recurrent small cell lung cancer: results from the CheckMate 032 randomised cohort. $J$ Thorac Oncol 2020; 15: 426-435.

Bondarenko I, Juan-Vidal O, Pajkos G, et al. Preliminary efficacy of durvalumab plus tremelimumab in platinum-refractory/resistant ED-SCLC from arm A of the phase II BALTIC study. Ann Oncol 2018; 29: viii596.

Chung HC, Piha-Paul SA, Lopez-Martin J, et al. Pembrolizumab after two or more lines of previous therapy in patients with recurrent or metastatic SCLC: results from the KEYNOTE-028 and KEYNOTE-158 studies. J Thorac Oncol 2020; 15: 618-627.

Ready N, Farago AF, de Braud F, et al. Third-line nivolumab monotherapy in recurrent SCLC: CheckMate 032. $J$ Thoracic Oncol 2019; 14: 237-244.

Ferrara R, Pilotto S, Caccese M, et al. Do immune checkpoint inhibitors need new studies methodology? $J$ Thorac Dis 2018; 10: S1564-S1580.

Antonia SJ, López-Martin JA, Bendell J, et al. Nivolumab alone and nivolumab plus ipilimumab in recurrent small-cell lung cancer (CheckMate 032): a multicentre, open-label, phase 1/2 trial. Lancet Oncol 2016; 17: 883-895.

Ricciuti B, Kravets S, Dahlberg SE, et al. Use of targeted next generation sequencing to characterise tumor mutational burden and efficacy of immune checkpoint inhibition in small cell lung cancer. $J$ Immunother Cancer 2019; 7: 87.

Bueno R, Stawiski EW, Goldstein LD, et al. Comprehensive genomic analysis of malignant pleural mesothelioma identifies recurrent mutations, gene fusions and splicing alterations. Nat Genet 2016; 48: 407-416.

Calabrò L, Morra A, Fonsatti E, et al. Tremelimumab for patients with chemotherapy-resistant advanced malignant mesothelioma: an open-label, single-arm, phase 2 trial. Lancet Oncol 2013; 14: 1104-1111.

Calabrò L, Morra A, Fonsatti E, et al. Efficacy and safety of an intensified schedule of tremelimumab for chemotherapy-resistant malignant mesothelioma: an open-label, single-arm, phase 2 study. Lancet Respir Med 2015; 3: 301-309.

3 Maio M, Scherpereel A, Calabrò L, et al. Tremelimumab as second-line or third-line treatment in relapsed malignant mesothelioma (DETERMINE): a multicentre, international, randomised, double-blind, placebo-controlled phase 2b trial. Lancet Oncol 2017; 18: 1261-1273.

4 Popat S, Curioni-Fontecedro A, Dafni U, et al. A multicentre randomised phase III trial comparing pembrolizumab versus single-agent chemotherapy for advanced pre-treated malignant pleural mesothelioma: the European Thoracic Oncology Platform (ETOP 9-15) PROMISE-meso trial. Ann Oncol 2020; 31: 1734-1745.

5 Nowak AK, Lesterhuis WJ, Kok PS, et al. Durvalumab with first-line chemotherapy in previously untreated malignant pleural mesothelioma (DREAM): a multicentre, single-arm, phase 2 trial with a safety run-in. Lancet Oncol 2020; 21: 1213-1223.

Forde PM, Sun Z, Anagnostou V, et al. PrE0505: Phase II multicenter study of anti-PD-L1, durvalumab, in combination with cisplatin and pemetrexed for the first-line treatment of unresectable malignant pleural mesothelioma (MPM) - A PrECOG LLC study. J Clin Oncol 2021; 38: Suppl. 15, 9003-9003.

Cedrés S, Ponce-Aix S, Zugazagoitia J, et al. Analysis of expression of programmed cell death 1 ligand 1 (PD-L1) in malignant pleural mesothelioma (MPM). PLoS ONE 2015; 10: e0121071.

Combaz-Lair C, Galateau-Sallé F, McLeer-Florin A, et al. Immune biomarkers PD-1/PD-L1 and TLR3 in malignant pleural mesotheliomas. Hum Pathol 2016; 52: 9-18.

9 Brosseau S, Danel C, Scherpereel A, et al. Shorter survival in malignant pleural mesothelioma patients with high PD-L1 expression associated with sarcomatoid or biphasic histology subtype: a series of 214 Cases From the Bio-MAPS Cohort. Clin Lung Cancer 2019; 20: e564-e575.

10 Inaguma S, Lasota J, Wang Z, et al. Expression of ALCAM (CD166) and PD-L1 (CD274) independently predicts shorter survival in malignant pleural mesothelioma. Hum Pathol 2018; 71: 1-7.

1 Thapa B, Salcedo A, Lin X, et al. The Immune microenvironment, genome-wide copy number aberrations, and survival in mesothelioma. $J$ Thorac Oncol 2017; 12: 850-859.

2 Losi L, Bertolini F, Guaitoli G, et al. Role of evaluating tumor-infiltrating lymphocytes, programmed death-1 ligand 1 and mismatch repair proteins expression in malignant mesothelioma. Int $J$ Oncol 2019; 55: 1157-1164.

13 Chee SJ, Lopez M, Mellows T, et al. Evaluating the effect of immune cells on the outcome of patients with mesothelioma. Br J Cancer 2017; 117: 1341-1348. 
114 Ujiie $\mathrm{H}$, Kadota $\mathrm{K}$, Ichi $\mathrm{NJ}$, et al. The tumoral and stromal immune microenvironment in malignant pleural mesothelioma: A comprehensive analysis reveals prognostic immune markers. Oncoimmunology 2015; 4; e1009285.

115 Pasello G, Zago G, Lunardi F, et al. Malignant pleural mesothelioma immune microenvironment and checkpoint expression: Correlation with clinical-pathological features and intratumor heterogeneity over time. Ann Oncol 2018; 29: 1258-1265.

116 Brockwell NK, Alamgeer M, Kumar B, et al. Preliminary study highlights the potential of immune checkpoint inhibitors in sarcomatoid mesothelioma. Transl Lung Cancer Res 2020; 9: 639-645

117 Ahmadzada T, Lee K, Clarke C, et al. High BIN1 expression has a favorable prognosis in malignant pleural mesothelioma and is associated with tumor infiltrating lymphocytes. Lung Cancer 2019; 130: 35-41.

118 Awad MM, Jones RE, Liu H, et al. Cytotoxic T cells in PD-L1-positive malignant pleural mesotheliomas are counterbalanced by distinct immunosuppressive factors. Cancer Immunol Res 2016; 4: 1038-1048.

119 Klampatsa A, O'Brien SM, Thompson JC, et al. Phenotypic and functional analysis of malignant mesothelioma tumor-infiltrating lymphocytes. Oncolmmunology 2019; 8: e1638211.

120 Hmeljak J, Sanchez-Vega F, Hoadley KA, et al. Integrative molecular characterisation of malignant pleural mesothelioma. Cancer Discov 2018; 8: 1548-1565.

121 Alcala N, Mangiante L, Le-Stang N, et al. Redefining malignant pleural mesothelioma types as a continuum uncovers immune-vascular interactions. EBioMed 2019; 48; 191-202.

122 Guo G, Chmielecki J, Goparaju C, et al. Whole-exome sequencing reveals frequent genetic alterations in BAP1, NF2, CDKN2A, and CUL1 in malignant pleural mesothelioma. Cancer Res 2015; 75: 264-269.

123 Nasu M, Emi M, Pastorino S, et al. High incidence of somatic BAP1 alterations in sporadic malignant mesothelioma. J Thorac Oncol 2015; 10: 565-576.

124 Yoshikawa Y, Emi M, Hashimoto-Tamaoki T, et al. High-density array-CGH with targeted NGS unmask multiple noncontiguous minute deletions on chromosome 3p21 in mesothelioma. Proc Natl Acad Sci USA 2016; 113: 13432-13437.

125 Shrestha R, Nabavi N, Lin YY, et al. BAP1 haploinsufficiency predicts a distinct immunogenic class of malignant peritoneal mesothelioma. Genome Med 2019; 11: 8.

126 Desai A, Karrison T, Rose B, et al. Phase II trial of pembrolizumab (NCT02399371) in previously-treated malignant mesothelioma (MM): final analysis. J Thoracic Oncol 2018; 13: Suppl., S339.

127 Okada M, Kijima T, Aoe K, et al. Clinical efficacy and safety of nivolumab: results of a multicenter, open-label, single-arm, Japanese phase II study in malignant pleural mesothelioma (MERIT). Clin Cancer Res 2019; 25: 5485-5492.

128 Baas P, Scherpereel A, Nowak A, et al. First-line nivolumab+opilimumab versus chemotherapy in unresectable malignant pleural mesothelioma: CheckMate 743. J Thorac Oncol 2020; 15: e42-e44.

129 Calabrò L, Morra A, Giannarelli D, et al. Tremelimumab combined with durvalumab in patients with mesothelioma (NIBIT-MESO-1): an open-label, non-randomised, phase 2 study. Lancet Respir Med 2018; 6 : 451-460.

130 Quispel-Janssen J, van der Noort V, de Vries JF, et al. programmed death 1 blockade with nivolumab in patients with recurrent malignant pleural mesothelioma. J Thorac Oncol 2018; 13: 1569-1576.

131 Alley EW, Lopez J, Santoro A, et al. Clinical safety and activity of pembrolizumab in patients with malignant pleural mesothelioma (KEYNOTE-028): preliminary results from a non-randomised, open-label, phase $1 \mathrm{~b}$ trial. Lancet Oncol 2017; 18: 623-630.

132 Hassan R, Thomas A, Nemunaitis JJ, et al. Efficacy and safety of avelumab treatment in patients with advanced unresectable mesothelioma: phase $1 \mathrm{~b}$ results from the JAVELIN solid tumor trial. JAMA Oncol 2019; 5: 351-357.

133 Disselhorst MJ, Quispel-Janssen J, Lalezari F, et al. Ipilimumab and nivolumab in the treatment of recurrent malignant pleural mesothelioma (INITIATE): results of a prospective, single-arm, phase 2 trial. Lancet Respir Med 2019; 7: 260-270.

134 Scherpereel A, Mazieres J, Greillier L, et al. Nivolumab or nivolumab plus ipilimumab in patients with relapsed malignant pleural mesothelioma (IFCT-1501 MAPS2): a multicentre, open-label, randomised, non-comparative, phase 2 trial. Lancet Oncol 2019; 20: 239-253.

135 Zalcman G, Mazieres J, Greillier L, et al. Second/third-line nivolumab versus nivo plus ipilimumab in malignant pleural mesothelioma: Long-term results of IFCT-1501 MAPS2 phase IIR trial with a focus on hyperprogression (HPD). Ann Oncol 2019; 30: v747.

136 Cantini L, Belderbos RA, Gooijer CJ, et al. Nivolumab in pre-treated malignant pleural mesothelioma: real-world data from the Dutch expanded access program. Transl Lung Cancer Res 2020; 9: 1169-1179.

137 Girard N, Ruffini E, Marx A, et al. Thymic epithelial tumours: ESMO Clinical Practice Guidelines for diagnosis, treatment and follow-up. Ann Oncol 2015; 26; Suppl 5, v40-v55.

138 Weissferdt A, Fujimoto J, Kalhor N, et al. Expression of PD-1 and PD-L1 in thymic epithelial neoplasms. Mod Pathol 2017; 30: 826-833. 
139 Padda SK, Riess JW, Schwartz EJ, et al. Diffuse high intensity PD-L1 staining in thymic epithelial tumors. J Thorac Oncol 2015; 10: 500-508.

140 Arbour KC, Naidoo J, Steele KE, et al. Expression of PD-L1 and other immunotherapeutic targets in thymic epithelial tumors. PloS One 2017; 12: e0182665.

141 Sakane T, Murase T, Okuda K, et al. A comparative study of PD-L1 immunohistochemical assays with four reliable antibodies in thymic carcinoma. Oncotarget 2018; 9: 6993-7009.

142 Giaccone G, Kim C, Thompson J, et al. Pembrolizumab in patients with thymic carcinoma: a single-arm, single-centre, phase 2 study. Lancet Oncol 2018; 19: 347-355.

143 Cho J, Kim HS, Ku BM, et al. Pembrolizumab for patients with refractory or relapsed thymic epithelial tumor: an open-label phase II trial. J Clin Oncol 2019; 37: 2162-2170.

144 Heery CR, O'Sullivan-Coyne G, Madan RA, et al. Avelumab for metastatic or locally advanced previously treated solid tumours (JAVELIN Solid Tumor): a phase 1a, multicohort, dose-escalation trial. Lancet Oncol 2017; 18: 587-598.

145 Katsuya Y, Horinouchi H, Seto T, et al. Single-arm, multicentre, phase II trial of nivolumab for unresectable or recurrent thymic carcinoma: PRIMER study. Eur J Cancer 2019; 113: 78-86. 